\title{
Paisaje, geología y arquitectura defensiva de la Guerra Civil Española en el sector sur-occidental de la sierra de Guadarrama. Una nueva metodología de investigación geo-arqueológica
}

\author{
José Manuel Baltuille Martín (1), Pablo Schnell Quiertant ${ }^{(2)}$ y Francisco Javier Rubio Pascual (3)
}

(1) Instituto Geológico y Minero de España. Ud. de Piedra Natural y Patrimonio Monumental. Rios Rosas, 23. 28003 Madrid. jm.baltuille@igme.es

(2) Asociación Española de Amigos de los Castillos (AEAC). Prado, 26. 28014 Madrid. pabloschnell@yahoo.es

(3) Instituto Geológico y Minero de España (IGME). Área de Geología, Geomorfología y Cartografía Geológica. Rios Rosas, 23. 28003 Madrid. f.rubio@igme.es

\section{RESUMEN}

El Instituto Geológico y Minero de España, junto con la Asociación Española de Amigos de los Castillos, inició en 2016 el proyecto "Paisaje, Geología y Arquitectura militar. Las construcciones defensivas del Frente de Madrid (1936-1939)". Siguiendo las corrientes actuales de colaboración entre equipos multidisciplinares, se han empleado tanto técnicas histórico-arqueológicas como geológicas. El estudio, enfocado en resaltar las características petrológicas y morfológicas de las construcciones (realizadas, preferentemente, en mampostería) y su ubicación espacial en su entorno, nos ha permitido desarrollar una metodología específica de trabajo.

Se ha estudiado un área de unas 13.000 ha en la sierra de Guadarrama, en los términos municipales de Robledo de Chavela, Santa María de la Alameda y Valdemaqueda, localizándose más de un millar de elementos arquitectónicos defensivos, de ambos bandos, que se clasifican en 18 tipologías de construcción.

El resultado final del proyecto permitirá a la sociedad, conocer y disfrutar del bagaje histórico, cultural y patrimonial que representan estos espacios, ampliando el concepto de paisaje natural al de paisaje geo-cultural.

Palabras clave: Guerra Civil Española, mampostería, metodología, patrimonio arquitectónico, sierra de Guadarrama.

\section{Landscape, geology and defensive architecture of the Spanish Civil War in the SW sector of the Guadarrama Range. A new methodology for geological-archaeological research}

\section{ABSTRACT}

The Geological and Mining Institute of Spain, in collaboration with the Spanish Association of Friends of the Castles, started the project "Landscape, Geology and Military Architecture in 2016. The defensive constructions of the Madrid Front (19361939)". Following the current trends of collaboration between multidisciplinary teams, both historical-archaeological and geological techniques have been used. This study, focused on highlighting the petrological and morphological characteristics of the constructions (preferably made of masonry) and their spatial location in their environment, has allowed us to develop a specific work methodology.

An area of about 13,000 ha has been studied in the Guadarrama Range, in the municipalities of Robledo de Chavela, Santa Maria de la Alameda and Valdemaqueda, where more than one thousand defensive elements have been located on both sides of the conflict, classified into 18 types of construction.

The final result of the project will allow society to know and enjoy the historical, cultural and heritage background that these spaces represent, replacing the concept of a natural landscape with that of a geo-cultural landscape.

Keywords: architectural heritage; Guadarrama Range; masonry, methodology; Spanish Civil War 


\section{Introducción}

El Instituto Geológico y Minero de España (IGME) inició, en 2016, el proyecto "Paisaje, Geología y Arquitectura militar. Las construcciones defensivas del Frente de Madrid (1936-1939)", para lo que contó con la colaboración de la Asociación Española de Amigos de los Castillos (AEAC). Este proyecto desarrolla una nueva estrategia metodológica para afrontar el estudio de las construcciones defensivas, no solo considerándolas como unos restos históricos aislados de su entorno físico, sino como elementos constitutivos de la morfología y del paisaje regional, gracias a los materiales constructivos empleados y a su ubicación espacial en el entorno. Esta línea, basada en el estudio de la piedra natural como un elemento constitutivo del patrimonio arquitectónico, la desarrolla el IGME, desde 2014, con el Programa INCHaPA (Baltuille Martín et al. 2016).

En la realización del proyecto, y siguiendo las corrientes actuales de colaboración entre equipos multidisciplinares, se emplean tanto técnicas arqueológicas e históricas como geológicas: determinación de elementos defensivos, análisis documental e histórico, caracterización litológica de los mampuestos, petrografía de rocas, análisis morfológico, etc. (Schnell Quiertant y Baltuille Martín, 2017).

\section{Los objetivos del proyecto son:}

- La caracterización y el estudio de los distintos sistemas defensivos existentes en el área de trabajo y su relación con el territorio, atendiendo tanto a los aspectos histórico-arquitectónico-militares, como a los eminentemente geológicos y paisajísticos.

- El diseño de una metodología específica de trabajo, tanto a nivel regional (sierra de Guadarrama) como para el entorno concreto de las posiciones; donde se complementen tanto técnicas geológicas y arqueológicas convencionales, junto con la incorporación de nuevas tecnologías de localización espacial (drones).

- El conocimiento del patrimonio arquitectónico defensivo de nuestra Guerra Civil, para favorecer su preservación y potenciar su aprovechamiento como fuente de desarrollo socio-económico de los núcleos poblacionales que lo habitan, muchos de ellos pertenecientes a lo que se denomina la "España vaciada".

No se trata, pues, de ningún tipo de inventario o catálogo de elementos defensivos, mejor o peor conservados, o una simple guía de campo, pues ya existen diversas publicaciones que abarcan estas temáticas de una forma muy completa (Castellano, 2004 y 2007; Arévalo, 2008; Pliego, 2009 y 2010).

El proyecto que da apoyo a este trabajo y la presente publicación, pretenden integrar la arquitectura defensiva con el paisaje y con la geología del mismo, tanto desde el punto de vista de la litología de los materiales empleados como desde el de la morfología del relieve circundante. A la vez trata de valorizar este recurso patrimonial de cara a su difusión, preservación y aprovechamiento socio-cultural, estableciendo una nueva metodología de investigación geo-arqueológica que, aunque ya ha sido utilizada en trabajos relacionados con el patrimonio arquitectónico-monumental (Álvarez Areces y Baltuille Martín, 2017; Álvarez Areces et al., 2016; Baltuille Martín et al., 2015 y 2018; Fernández Suárez et al., 2017), nunca se había aplicado al patrimonio arquitectónico defensivo relacionado con la Guerra Civil Española.

Los restos materiales de la guerra, de los cuales los elementos fortificados son una parte importante, no han comenzado a valorarse, socialmente, hasta hace poco tiempo. No profundizaremos en las razones de este desinterés, pero podemos considerar, que son la manifestación material de un pasado incómodo (González Ruibal, 2008).

\section{Antecedentes históricos}

Al tratarse de un trabajo donde una parte importante del mismo se relaciona estrechamente con una serie de hechos que, a pesar del tiempo transcurrido, aún conllevan una gran carga emocional, creemos conveniente hacer una breve reseña histórica de los hechos que llevaron al establecimiento de un frente bélico estable en la sierra madrileña.

Con el levantamiento en Melilla de las tropas de África, el 17 de julio de 1936, dio comienzo una sangrienta y devastadora guerra civil que no finalizó hasta el 1 de abril de 1939 y que ha marcado la historia de España de los últimos 80 años.

La idea original del alzamiento era la rápida convergencia, sobre Madrid, de tropas sublevadas y milicias traídas de zonas favorables al golpe (Navarra y Castilla la Vieja, principalmente) que apoyarían a los cuarteles de la capital y cercenarían así cualquier posible reacción del gobierno republicano; pero la rápida reacción de las tropas leales y de las organizaciones obreras, armadas por el gobierno, abortó esa posibilidad. Desde entonces el objetivo del mando republicano fue cerrar los pasos montañosos que, a través de la sierra, comunicaban las amplias Ilanuras castellanas, en poder de los sublevados, con la capital. Tras violentos combates, el avance quedó detenido en los puertos de Guadarrama, Navacerrada y Somosierra.

La sierra de Guadarrama presentaba, respecto a las de Somosierra o Navacerrada, unas características físicas que la hacían más estratégica de cara a la 
ocupación o defensa de Madrid. Su escasa distancia a la capital (unos $60 \mathrm{~km}$ ), la existencia de buenas vías de comunicación, tanto por carretera como por ferrocarril, su morfología agreste con elevaciones como el Alto del León, Abantos, Cueva Valiente y Cabeza Líjar y que se continuaban, hacia el oeste, con la sierra de Malagón y de La Paramera y la presencia, en diversas zonas, de masas forestales (pinares) importantes.

Aparte de las características objetivas descritas, existía una relación emocional entre la sierra de Guadarrama y la sociedad madrileña, la sierra era un punto de esparcimiento para la población que, o bien veraneaba en la multitud de pueblos serranos o disfrutaba de un día de excursión familiar entre sus pinares. Esa estrecha relación hace que, ya el mismo sábado 18 de julio, aparezcan diversas partidas de civiles que ocupan el Alto del León y los pinares próximos hasta San Rafael. El día 21, desde el bando gubernamental, se dictan órdenes para que se ocupen los pasos de las sierras madrileñas; $y$ ese mismo día por la tarde, una columna de un millar de hombres al mando del coronel Castillo, compuesta por tropas de ferrocarriles, guardias de asalto, guardia civil, artillería y milicianos, llega a Villalba y, al amanecer del día 22, deja ocupado el Alto del León.

Mientras tanto, en el bando contrario, en la tarde del día 21 se constituye en Valladolid una columna de unos 800 hombres, al mando del coronel Serrador, con tropas de infantería del Regimiento San Quintín, caballería, artillería, transporte y dos centenares de civiles, con el objetivo de tomar la sierra. A las dos de la tarde del día 22 se encuentran ya en San Rafael, reforzados con una compañía de ametralladoras que se les había unido en Villacastín y otra pequeña columna, al mando del capitán Guiloche, que se les incorporó en El Espinar, hasta alcanzar un total de 900 efectivos. Inmediatamente inician el asalto y, a las siete y media de la tarde, toman definitivamente el Alto del León.

La lucha, en el sector del Alto del León, se desarrolla entre el 22 de julio (fecha en que los nacionales toman el Alto) y el 15 de septiembre (cuando ocupan la cumbre de Cabeza Líjar, asegurando así el flanco oeste del Alto). Durante esas fechas operaron en la sierra varias columnas gubernamentales que obtuvieron penetraciones considerables en territorio enemigo, estando a punto de tomar Ávila la mandada por el teniente coronel Mangada. Así, las columnas de Rubio y de Mangada, detuvieron el ataque nacional sobre Peguerinos, infringiendo una severa derrota a las fuerzas rebeldes que trataban de infiltrarse, para atacar El Escorial y Las Navas del Marqués (Martínez Bande, 1982).

En el mes de octubre, en el teatro de operaciones que dibujan las cumbres del Guadarrama (al norte) y el valle delTajo (sur), queda ocupado por dos ejércitos con estrategias totalmente diferentes. Uno en actitud claramente defensiva y desplegado para proteger el acceso a Madrid, como es el caso de las fuerzas gubernamentales del general Asensio, que cuenta con 25.000 hombres; enfrentado a otro, el nacional (14.000 hombres), en pleno despliegue victorioso desde la toma de Badajoz y tras su ascenso por tierras extremeñas y que acababa de alcanzar el éxito de liberar el Alcázar de Toledo, el 28 de septiembre, con toda la carga moral y propagandística que ello conlleva. Las operaciones sobre el sector serrano se inician el día 6 de octubre, quedando el día 11 ocupadas las principales localidades de la zona: Sotillo de la Adrada, San Martín de Valdeiglesias, Cebreros y Cadalso de los Vidrios. Entre el 14 y el 22 de octubre los sublevados continúan su ascenso hacia el norte y toman Valdemaqueda, Robledo de Chavela y Las Navas del Marqués, quedando Peguerinos y Santa María de la Alameda en manos gubernamentales, estableciéndose en ésta última localidad el cuartel general de la columna Mangada. Con estas operaciones el ejército del general Mola fortalece su flanco izquierdo, en su avance hacia Madrid a través de la Cuenca delTajo, quedando en la zona estabilizado el frente hasta el final del conflicto; procediendo, ambos bandos, a fortificarlo fuertemente, en un proceso acelerado que duró hasta el final de la guerra.

En nuestra zona de estudio el frente defensivo tuvo las características que impone la montaña: discontinuidad en la distribución y distancia variable entre enemigos, que en ocasiones era de varios quilómetros y en otras, casi inmediata.

Como acabamos de ver, la unidad táctica empleada por ambos bandos, en los primeros meses de la guerra, era la columna. Se trataba de un núcleo armado bien conocido en el ejército español, por haber sido utilizado, ampliamente, en las campañas africanas de principios del siglo $X X$. De composición heterogénea estaba formada por fuerzas militares y de orden público, así como por elementos voluntarios civiles. Las fuerzas militares, que correspondían a unidades operativas incompletas del ejército, eran generalmente tropas de infantería, artillería e ingenieros y contaban con medios propios de transporte, lo que les daba su mayor virtud, la movilidad.

Estas columnas, enfrentadas en los primeros compases de la guerra, se transformaron en unidades más convencionales con el discurrir de los meses.

Así, tras los fracasos militares gubernamentales de los primeros meses, en el otoño de 1936, el gobierno de Largo Caballero impulsa la reconversión de las Milicias en el Ejército Popular de la República; lo que conlleva la creación de la Brigada Mixta como unidad 
combatiente en el bando republicano, llegándose a crear hasta un total de 247 brigadas a lo largo de toda la guerra (Engel, 2005). Sin embargo, en el denominado bando nacional, es la División la unidad estratégica de combate; con lo que se mantiene la estructura existente en el ejército español al comienzo del conflicto, aunque se procedió a un cambio de numeración, para paliar aquellas unidades que habían quedado bajo dominio gubernamental.

\section{Zona de estudio}

Las características tan particulares del proyecto, el estudio de la arquitectura defensiva de la Guerra Civil Española y su interrelación con la morfología circundante y los materiales constructivos empleados, sugerían áreas geográficas donde los frentes debían tener características muy precisas:

- Urgencia en su trazado y, por ello, precariedad de los mismos; debido a la premura con que se generaban los acontecimientos históricos del momento (ello obligaba al aprovechamiento de los recursos más próximos y al autoabastecimiento)

- Componente morfológica y topográfica fuerte (ello implicaba escasez de vías de comunicación y falta de intendencia)

- Estabilidad y larga duración de los mismos (ello facilitaba la fortificación de las unidades)

- Proximidad a la capital del Estado (debido a la importancia que la caída o no de Madrid, en el primer año de conflicto, supuso para los dos bandos y las posibilidades que ello conllevaba)

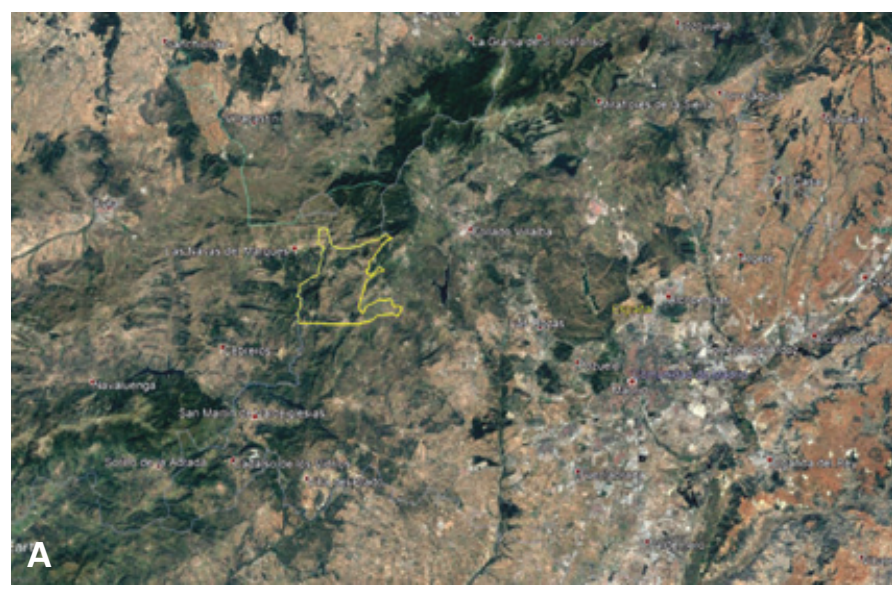

Todo ello hizo que se escogiera, para este estudio, la sierra de Guadarrama; y en concreto, su sector más sur-occidental, el integrado por los municipios de Robledo de Chavela, Santa María de la Alameda y Valdemaqueda, en la Comunidad de Madrid (Fig. 1).

El área de estudio ocupa una superficie de $132 \mathrm{~km}^{2}$ o, lo que es lo mismo, 13.244 ha. La altura media es de unos $1.250 \mathrm{~m}$, siendo sus principales elevaciones: Los Tientos (1.754 m), Peña del Trueno $(1.415 \mathrm{~m})$ y Peña Manotera $(1.345 \mathrm{~m})$ al norte; La Atalaya $(1.372 \mathrm{~m})$ y Santa Catalina (1.386 m) al oeste; Puerto de Malagón (1.536 m), Cerro de la Cabeza (1.679 m), Cerro de la Cancha $(1.801 \mathrm{~m})$, Puerto de la Paradilla $(1.347 \mathrm{~m})$, Puerto de la Cruz Verde (1.257 m) y Cerro de San Benito $(1.626 \mathrm{~m})$ al este, Cerro de Valdemadera $(1.398 \mathrm{~m})$, Alto de la Mora (1.351 m), Cerro Cabezuelo (1.487 m) y Cerro Calamocho (1.432 m) en la zona central y San Pedro $(1.021 \mathrm{~m})$, Cerro de Robledillo $(1.075 \mathrm{~m})$ y Los Morros (1.081 m) al sur).

La población total de la zona asciende a 6.305 habitantes, según datos del INE (2019), lo que da una densidad media de población de 28,71 hab. $/ \mathrm{km}^{2}$, que se reparte entre once núcleos de población, de los cuales ocho corresponden a Santa María de la Alameda: La Estación, Navalespino, Robledondo, La Hoya, La Paradilla, Las Herreras y El Pimpollar. Además, existen cinco núcleos poblacionales abandonados, La Cereda (t.m. de Santa María de la Alameda) y Navahonda, Los Degollados, Fuentelámpara y La Carbonera (t.m. de Robledo de Chavela).

El área, en una gran extensión de su superficie, cuenta con una serie de grandes fincas dedicadas a la ganadería o a la cinegética; lo que nos ha obliga-

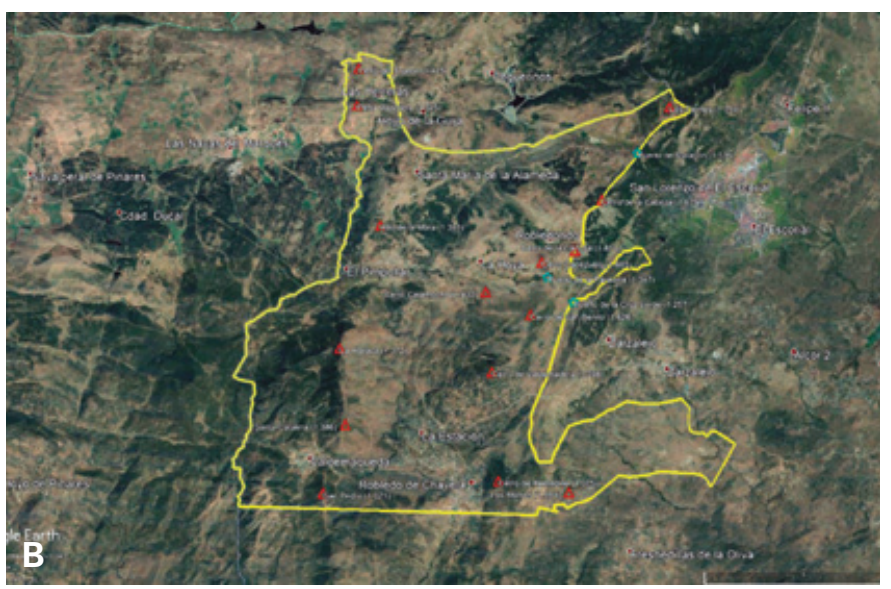

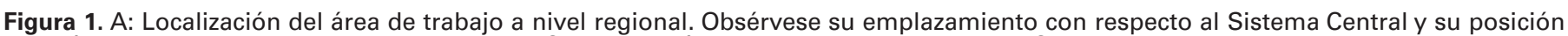

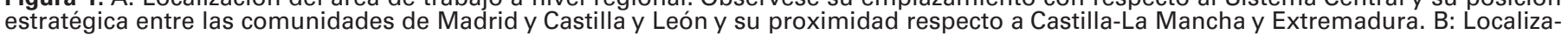
ción de las principales elevaciones y cumbres de la zona (imágenes obtenidas de Google Earth Pro).

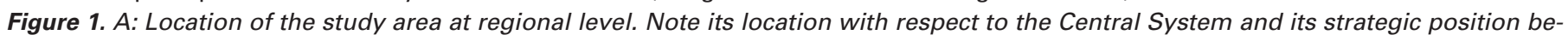

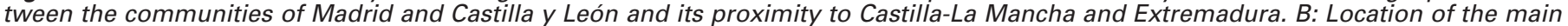
elevations and peaks in the area (images obtained from Google Earth Pro). 
do a realizar un esfuerzo muy elevado para obtener las autorizaciones correspondientes y poder acceder a ellas y realizar el trabajo. No obstante, hemos contado con una gran colaboración y el esfuerzo ha tenido una gran recompensa, pues se han localizado conjuntos defensivos y obras desconocidas hasta ahora.

\section{Marco geológico}

El área de estudio se localiza en la Zona Centro Ibérica del Macizo Hercínico (Julivert et al., 1972), en el límite entre el Dominio Occidental y Central del Sistema Central Español (Bellido et al., 1981). Los materiales que afloran pertenecen al conjunto ígneo y metamórfico del Macizo Hercínico y presentan edades quevarían de cámbricas a ordovícicas. Estos materiales, ortognéisicos y metasedimentarios, constituyen parte del afloramiento de El Escorial-Villa del Prado (Fig. 2).

Las rocas más representadas son los ortogneises glandulares que, atendiendo a criterios petrográficos, presenta tres tipos principales: ortogneises glandulares comunes, melanocratos y con glándulas homométricas. Están compuestos de feldespato potásico, plagioclasa, cuarzo y biotita, acompañados por cantidades variables de sillimanita y moscovita secundaria, y distena y granate en las variedades melanocratas.

Los ortogneises glandulares comunes presentan estructuras gnéisicas oftalmíticas, definidas por abundantes megacristales de feldespato potásico, de 2-6 $\mathrm{cm}$, cuyos hábitos varían entre subidiomorfos y alotriomorfos. Pueden aparecer migmatizados (parcialmente fundidos). Los melanocratos se encuentran en bandas fuertemente deformadas y se asocian con materiales metasedimentarios, siendo la coloración de matriz muy oscura por su composición biotítica. En el caso de los glandulares homométricos, sus glándulas presentan una distribución bimodal, siendo de feldespato potásico las de mayor tamaño y de plagioclasa las de menor. La coloración de la matriz es muy oscura por su riqueza en biotita.

Asociados a los ortogneises glandulares, como cuerpos menores, aparecen leucogneises en bandas decimétricas a decamétricas, mediante contactos netos; hay que resaltar, por su tamaño, el que transcurre a lo largo del río Cofio, afectado por una banda de cizalla en su borde occidental. Su composición es cuarzofeldespática y con escasa proporción de micas, presentando granate, andalucita o sillimanita, como minerales accesorios. En los afloramientos del Cerro de San Benito aparecen, junto al granate, distena residual incluida en plagioclasas.

Los contactos de todos estos ortogneises, tanto entre sí como con los metasedimentos, tienen carácter

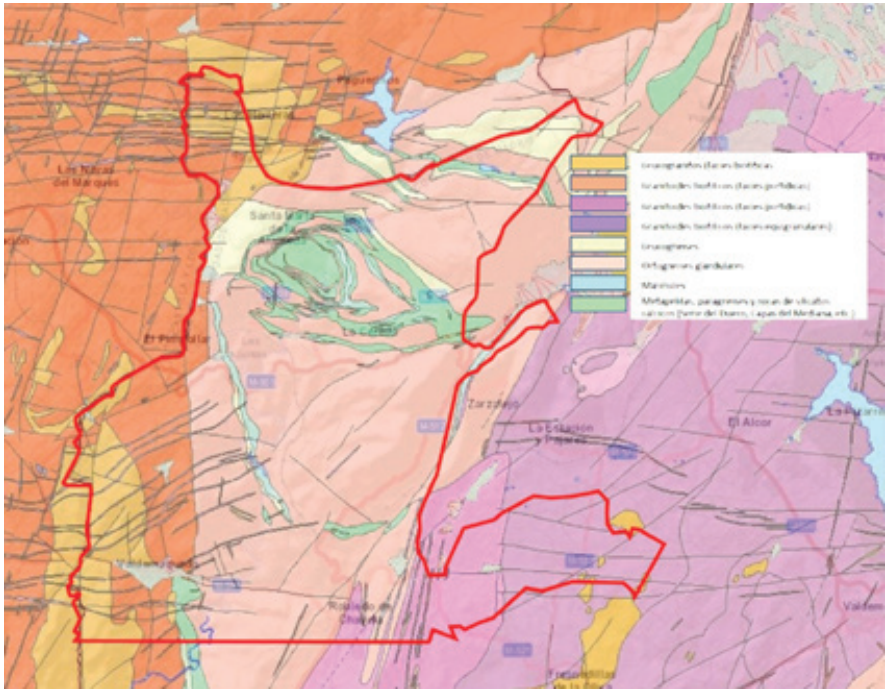

Figura 2. Esquema geológico con la representación de las distintas facies que afloran en la zona de estudio (extraído del Navegador del Mapa Geológico Digital Continuo, IGME).

Figure 2. Geological diagram with the representation of the different facies that appear in the study area (extracted from the Navigator of the Continuous Digital Geological Map, IGME).

intrusivo y son, en general, netos y estructuralmente concordantes, debido a la fuerte deformación que los afecta y que transpone los contactos originales.

Los materiales metasedimentarios están constituidos por rocas de composición original pelítica y grauváquica y por mármoles y rocas calcosilicatadas. Todos ellos están muy deformados y recristalizados, pudiendo aparecer migmatizados los de naturaleza pelítico-grauváquica. Estos metasedimentos sólo aparecen en el núcleo de la estructura de Santa María de la Alameda, en forma de estrechas bandas en zonas de cizalla, donde son cabalgados por ortogneises glandulares.

Los materiales metapelíticos son esquistos y gneises bandeados micáceos que, debido a la migmatización, presentan estructuras que varían de estromáticas a esquistosas. Su composición principal es cuarzo, plagioclasa, biotita y sillimanita, con cordierita. Los materiales de ascendencia metasamítica son más pobres en micas y más ricos en cuarzo y plagioclasa.

Los niveles carbonatados presentan potencias de 10-20 m, pero pierden continuidad por fenómenos de "boudinage". Estas rocas están transformadas en mármoles bandeados calcítico-dolomíticos, con texturas granoblásticas y colores ocres a blanquecinos. Su composición principal calcítico-dolomítica, se complementa con cantidades menores de flogopita, diópsido, forsterita, clinohumita, espinela y otra serie compleja de silicatos cálcico-magnésicos menos frecuentes; sin embargo, la banda que transcurre por el Puerto de la Cruz Verde, cambia su composición calcítico-dolomítica por magnesítica. 
Generalmente, asociados a los niveles carbonatados, aparecen delgados niveles de rocas con silicatos cálcicos. Sin embargo, en el borde entre los ortogneises de La Hoya y las metapelitas, en la parte externa de la estructura de Santa María de la Alameda, (Arroyo. de Robledondo, en el collado entre los cerros Calamocho y Cabezuelo), aflora un skarn no asociado, de manera visible, a ningún paquete carbonatado. También en el Arroyo de la Umbría, al NE de La Paradilla, aparecen niveles métricos de un skarn de color oscuro, grano muy fino, y compuesto por flogopita, plagioclasa (andesina-labrador), cuarzo intersticial y pirrotina.

Las rocas graníticas hercínicas, representadas en el área de estudio, se corresponden con varios tipos de granitoides biotíticos, preferentemente adamellitas, y leucogranitos.

En la zona SE del área de estudio, entre Robledo de Chavela y Zarzalejo, nos encontramos una unidad plutónica compuesta, fundamentalmente, por adameIlitas biotíticas con transiciones a tipos granodioríticos biotíticos. Texturalmente, y de $\mathrm{E}$ a $\mathrm{O}$, puede definirse una variedad equigranular y otra porfídica; el límite entre ambas presenta, generalmente, un carácter transicional en forma de una banda de adamellitas con megacristales cuya adscripción, a unas u otras, es problemática.

Las facies equigranulares son rocas de grano medio o medio-grueso, con tamaños de cristales entre 2-5 $\mathrm{mm}$, pudiendo alcanzar hasta los $7 \mathrm{~cm}$. La proporción de biotita varía entre el 10-15\% presentándose, generalmente, como plaquitas poco idiomorfas y de pequeño tamaño. En las zonas próximas al contacto con las facies porfídicas, suelen aparecer megacristales de feldespato potásico, de entre 1-3 cm de tamaño. Su composición mineralógica es: cuarzo, plagioclasa, feldespato potásico y biotita, como minerales principales, junto con cordierita y moscovita. Como minerales secundarios: epidota, clorita, titanita, sericita, pinnita y prehnita, y como accesorios aparecen, apatito, circón, ilmenita y, esporádicamente, monacita.

Las facies porfídicas son rocas con megacristales de feldespato potásico, con tamaños que oscilan entre $1-3 \mathrm{~cm}$ y secciones rectangulares gruesas, $y$ cuya matriz es de grano medio (3-4 mm). Presenta un contenido en biotita entre el 10-13\%, aunque también se presenta en forma de agregados policristalinos que, en general, son menores y menos abundantes que en las adamellitas equigranulares. Afloran al E de Robledo de Chavela, fuertemente imbricadas con bandas de materiales metamórficos (gneises glandulares); siendo muy frecuentes las estructuras fluidales, allí donde la deformación no es apreciable, formándose bandas de concentración de biotita y/o de fenocristales. Presentan cuarzo, plagioclasa, feldespato potásico y bio- tita, como minerales principales; como minerales secundarios: epidota, clorita, titanita, sericita y prehnita, y como accesorios aparecen, apatito, circón, ilmenita $y$, ocasionalmente, moscovita.

Los enclaves más frecuentes (gabarros), en ambos tipos texturales, son los de composición tonalítica, textura microgranuda y grano fino a muy fino, donde pueden encontrarse fenocristales dispersos de cuarzo y feldespato. Presentan, generalmente, formas subredondeadas o elipsoidales y su tamaño y densidad varía mucho; aunque en canteras al sur de Zarzalejo, se han encontrado algunos que superan el metro. También, aunque en menor proporción, aparecen enclaves de rocas metamórficas (ortogneises glandulares migmatizados), de pequeñas dimensiones, salvo en zonas inmediatas a los contactos. Presentan formas angulosas $y$, generalmente, aplanadas. Toda esta unidad adamellítica se correspondería con la unidad de adamellitas biotíticas de grano medio, tipo Zarzalejo-Valdemorillo, de Bellido Mulas et al. (1990a).

En la parte más occidental del área, y con una disposición N-S, aparecen unas adamellitas hipidiomorfas de grano medio a grueso; presentando porfidismo variable y fenocristales de feldespato potásico de 2-5 $\mathrm{cm}$ de longitud. Están constituidas por cuarzo, ortosa, plagioclasa, biotita y apatito, a veces abundante, como minerales principales y circón, monacita y allanita como accesorios. Presentan como característica la episienitización, en formas irregulares o bandas. Sus afloramientos generalmente son en forma de "lehm" granítico, aunque a veces, en zonas de cumbres u hombreras, se presentan como berrocales 0 lanchares. Estas rocas, post o sincinemáticas, se corresponden con las denominadas adamellitas con megacristales y microagregados biotíticos, tipo Navas del Marqués (Bellido Mulas et al. (1990b).

Las rocas ígneas descritas se complementan con unos cuerpos leucograníticos, muy extendidos por el área. Se trata de leucogranitos muy homogéneos, de grano medio a medio-fino hacia el borde, con cavidades miarolíticas frecuentes y bolsadas pegmatíticas. EI feldespato potásico, ortosa, está ligeramente transformado a microclina y la plagioclasa (albita-oligoclasa) muestra zonación y bordes albíticos. Los minerales secundarios son biotita verde, clorita, clinozoisita y titanita y, los accesorios, circón, apatito y allanita. Asociados al Plutón de Las Navas aparecen, en su periferia, cuerpos leucograníticos intrusivos de gran tamaño, como el stock delTurral, alargado y de dirección norteada. Estos macizos, que tienden a dar resaltes morfológicos $y$, a veces, aparecen asociados a zonas de fracturas, presentan tonalidades rojizas y silicificaciones.

Finalmente, citaremos los diferentes tipos de rocas filonianas que atraviesan el área de trabajo y que se 
circunscriben a diques de pórfidos graníticos, cuarzo y lamprófido. Los más abundantes, con mucha diferencia, son los pórfidos graníticos, que atraviesan las estructuras precinemáticas en dirección E-O. Presentan potencias de 10 a $40 \mathrm{~m}$ y buzamientos casi verticales $(70-80 \% / N)$. Presentan textura porfídica y variación del tamaño de grano desde el centro a los bordes. Composicionalmente presentan cuarzo, ortosa (en macla de Carlsbad) y plagioclasa zonada como minerales principales; circón, apatito y allanita, como accesorios y clorita, epidota, sericita y titanita como secundarios.

Respecto a los diques de cuarzo en la zona aparecen dos, de dirección $\mathrm{N} 10-20^{\circ}$ y subverticales y dimensiones muy diferentes. El principal, con unos $2.400 \mathrm{~m}$ de longitud y una anchura máxima de $55 \mathrm{~m}$, corta la carretera M-521, Villanueva de la Cañada-Robledo de Chavela, a la altura del km 27, en la Dehesa de Fuentelámpara; el segundo, que presenta $700 \mathrm{~m}$ de longitud y $65 \mathrm{~m}$ de anchura máxima, corta la carretera M-538, Santa María de la Alameda- La Paradilla, entre el km 1,5 y el 3, en el paraje de la Solana de la Fuente.

Por último, y a nivel testimonial, citaremos un dique de lamprófido, de $45 \mathrm{~m}$ de espesor y $260 \mathrm{~m}$ de longitud, situado al E de Las Herreras, en el paraje de Las Tejoneras.

No podemos terminar este apartado sin hacer referencia al potencial extractivo de la zona, respecto a las rocas de construcción, dado la utilización que tuvo su aprovechamiento a lo largo del conflicto civil. Gran tradición histórica ha tenido la cantería granítica en toda esta zona occidental de la sierra de Guadarrama. Sobresale la zona de Hoyo de Pinares, al NO de la población, así como el área SO de Las Navas del Marqués. Sin olvidar otras localidades próximas, con amplia tradición histórica en cantería, tales como: San Lorenzo de El Escorial, Alpedrete, Zarzalejo, etc.; ya que, prácticamente, cualquier pueblo de la zona ha tenido actividad extractiva en los afloramientos de rocas graníticas y metamórficas del entorno, lo que ha supuesto una de sus principales fuentes de ingreso.

\section{Resultados}

Poner de manifiesto la importancia de la geología, en su más amplio sentido, en todo lo referente a la arquitectura defensiva y a la ciencia militar: materiales pétreos usados, caracterización del sustrato rocoso, morfología del emplazamiento, valoración de los recursos naturales a proteger, ordenación del territorio respecto a los cursos de agua y vías de comunicación, etc., es una aportación imprescindible y estratégica para valorizar el peso de la geología en trabajos multidisciplinares relacionados con este tipo de patrimo-

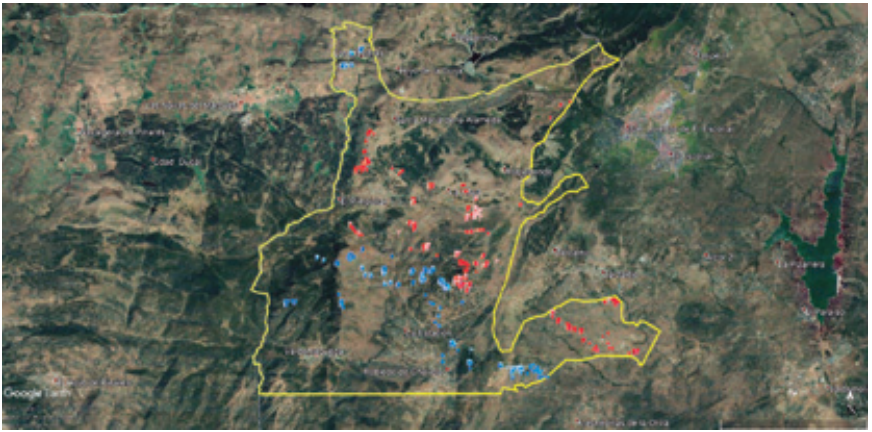

Figura 3. Distribución de los elementos defensivos localizados (imagen obtenida de Google Earth Pro).

Figure 3. Distribution of located defensive elements (image obtained from Google Earth Pro).

nio. ¡Sólo el desconocimiento o la estulticia puede ignorar la importancia que la geología tiene en el ámbito de la ciencia militar!.

Ya en plena Guerra Civil, en el que posiblemente sea el mejor tratado de fortificación de toda la contienda (Capdevila, 1938), se resaltaba inequívocamente la importancia de la geología en el arte de la fortificación: "El terreno, en donde la organización defensiva en general se ha de instalar, debe corresponder ante todo a las necesidades tácticas, pero inmediatamente después a las condiciones geológicas del suelo".

Así, este trabajo, pretende ser un primer avance de los resultados obtenidos en el proyecto, dado el volumen de información obtenida en él; información qué, en breve, se recogerá en una monografía específica.

Los resultados obtenidos, a lo largo de los tres años del proyecto, han sido los siguientes:

- Realización de diversas campañas de campo en los términos municipales de Santa María de la Alameda, Robledo de Chavela y Valdemaqueda, con el resultado de más de 13.000 ha estudiadas.

- Localización, estudio y caracterización de un total de 1.016 elementos constructivos defensivos (36\% republicanos y $64 \%$ nacionales), de los cuales un $85 \%$ están realizados con mampostería, bien a hueso o con mortero de cemento.

- Adscripción de los elementos estudiados a un total de 54 posiciones o conjuntos defensivos (CoDe's), 29 republicanos y 35 nacionales (Fig. 3); varios de los cuales, con todos sus elementos constructivos, son documentados y estudiados por primera vez, gracias a este proyecto.

- Definición y carga de una base de datos específica para el almacenamiento de la información obtenida durante las campañas de campo, con un total de 86 campos: organización (5), localización (17), caracterización (8), técnicas constructivas y materiales (10), 

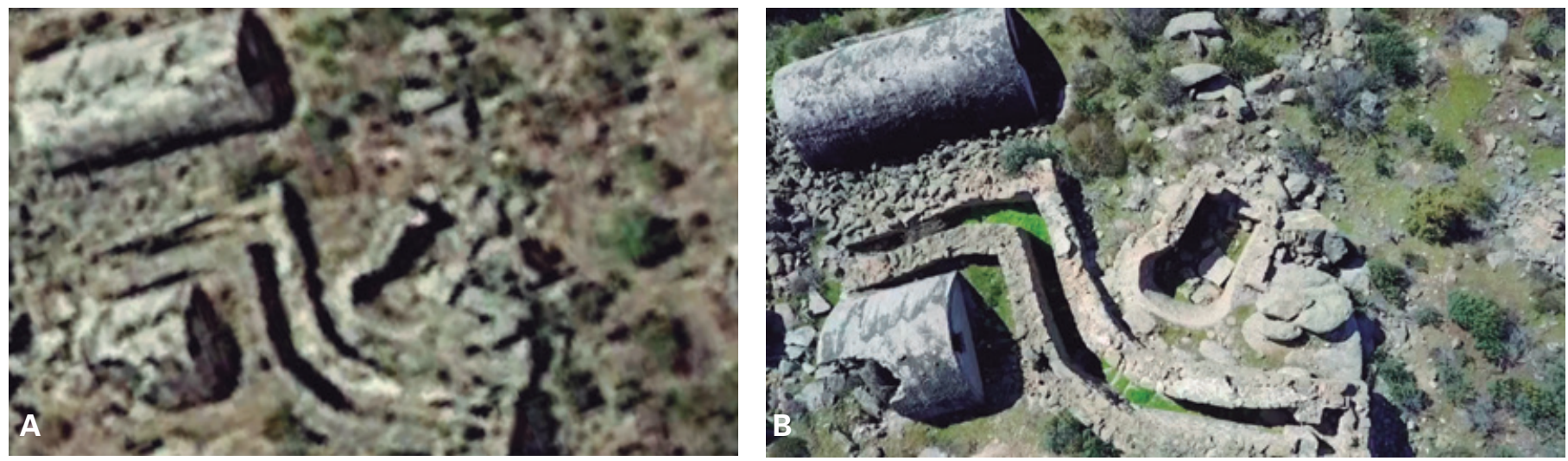

Figura 4. Mejora en la definición de la imagen para la localización de objetivos en campo. A: Imagen obtenida de Google Earth Pro. B: Imagen obtenida con dron.

Figure 4. Improved image definition for the location of targets in the field. A: Image obtained from Google Earth Pro. B: Image obtained with a drone.

estado y protección (10), características militares (7), catastro y propiedad (9), geología (9), documentación (7) y gestión y control (9)

- Obtención de un fondo documental gráfico de más de cuatro mil fotografías en color

- Muestreo de los principales conjuntos defensivos construidos con mampuesto y caracterización petrológica y petrográfica de la litología empleada, para confirmar diversos aspectos litológicos y geológicos.

- Estudio fotogramétrico aéreo mediante un dron DJI Mavic Pro, dotado con cámara de 12,71 pixeles (Fig. 4).

- Tratamiento digital de las imágenes (modelos en 2D, 3D, MDT, etc.)

-Análisis geomorfológico del paisaje y su posterior representación en un SIG

Antes de iniciar la descripción de los principales tipos de construcciones localizadas, junto con sus características particulares, queremos hacer una reflexión sobre un término que pensamos que se emplea, en la literatura relacionada con aspectos de la Guerra Civil, de una manera ligera e inexacta, lo que conlleva a confusiones y errores en las dataciones y localizaciones de diferentes construcciones defensivas. Nos estamos refiriendo al término "posición" que, teniendo un significado concreto y perfectamente definido, vemos como con frecuencia se utiliza olvidando una de sus principales características, la temporalidad. El término posición se da al "emplazamiento geográfico de una unidad militar concreta, cualquiera que sea su tamaño, desplegada en un frente determinado y en un momento concreto del devenir histórico del conflicto". Generalmente sus denominaciones se cambiaban por diferentes motivos: cambios propuestos desde los Cuarteles Generales, por motivos estratégicos o tácticos (cambio de denominaciones nominales por otras numerales), por cambiar el responsable que la dirigía o la unidad que la ocupaba y que había dado nombre a la misma, por una rectificación del frente, etc.; cualquiera de esas circunstancias se olvida, con el consiguiente error que ello conlleva, cuando se utiliza la denominación de una posición como de algo inmutable. Por ello proponemos el término Conjunto Defensivo (CoDe) como "la agrupación de obras y elementos defensivos, asociados a un entorno geográfico concreto y con una teórica capacidad de fuego que la dota de personalidad propia e independiente. Su denominación específica está ligada a lugares, tradiciones orales, o nombres propios" y entendemos que esta denominación es menos equívoca que la de posición, que sólo debería aplicarse atendiendo a frentes concretos y a periodos temporales específicos $\mathrm{y}$, siempre, contando con referencias contrastadas; como haremos en las conclusiones del proyecto, donde presentaremos un cuadro completo de correlaciones entre CoDe's y posiciones, y donde veremos que éstas varían según los diferentes momentos temporales.

Los 1.016 elementos defensivos localizados, se han clasificado en un total de 18 tipologías diferentes, que a su vez se agrupan en tres grandes grupos de elementos defensivos según las funciones que desempeñan: vistas, protección o fuego, más un cuarto grupo que reúne aquellos que no pueden englobarse en los anteriores (Tabla 1). El grupo con mayor representación es, lógicamente, el grupo relacionado con el potencial de fuego $(64,66 \%)$, posteriormente el relacionado con la protección de la tropa $(29,82 \%)$, después el grupo de "Otros elementos" $(3,94 \%)$ y, finalmente, los relacionados con las vistas (1,58 \%). 


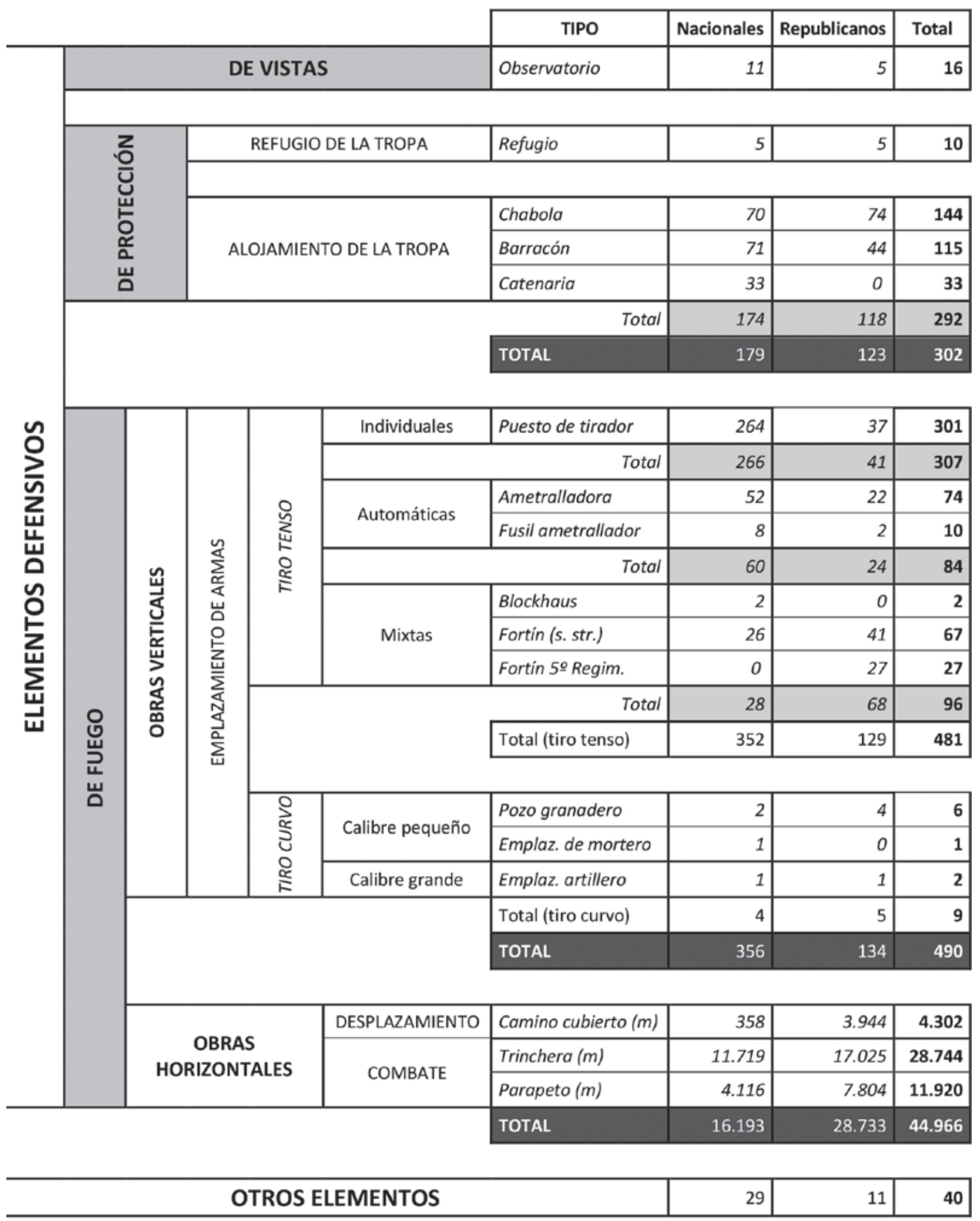

Tabla 1. Caracterización tipológica de los diferentes elementos defensivos estudiados.

Table 1. Typological chart of the different defensive elements studied. 

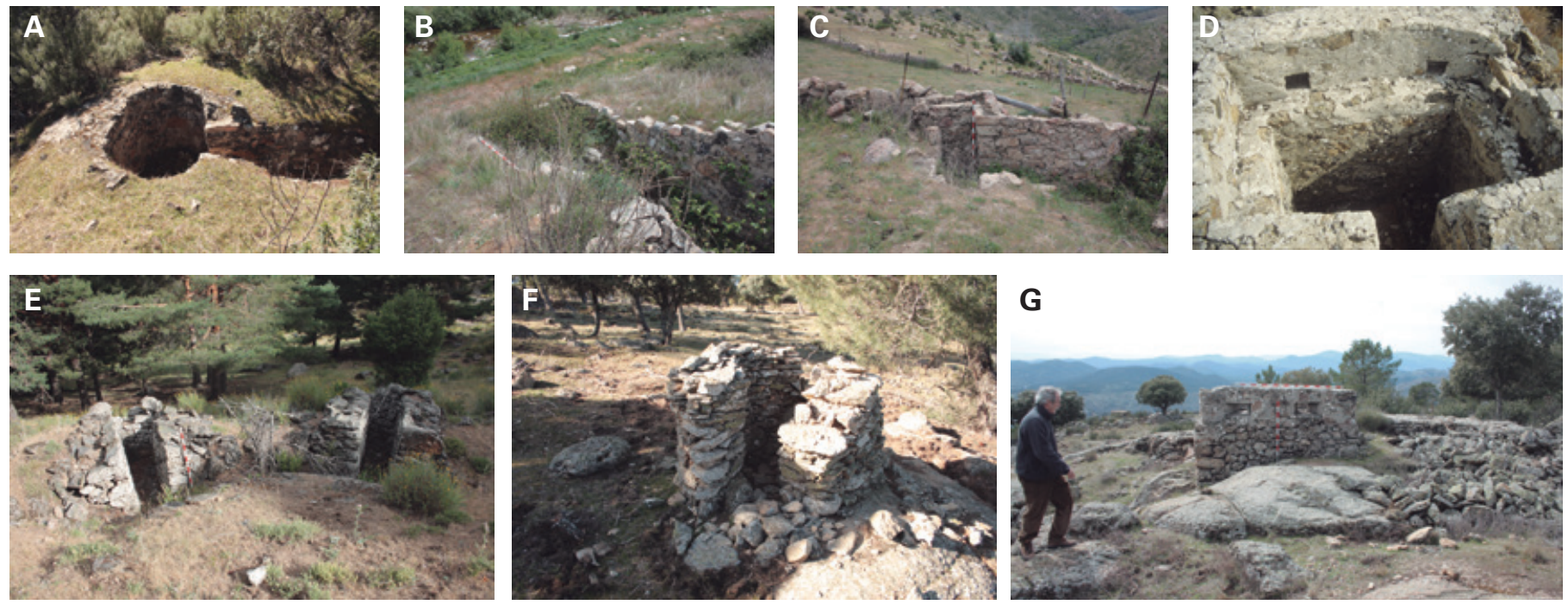

Figura 5. Puestos de tirador. A: Circular (Matiazo/n, $R C H^{*}$ ). B: En pasillo (Valdemaqueda 1/n, VMQ). C: En falsaT (Peña Mocha Baja/n, SMA). D: EnT con parapeto (Ciudad Prohibida/n, SMA). E: En U (Muro Largo/r, SMA). F: En C (Muro Largo/r, SMA). G) Vista general del PT de la fig. 5D. (*).- Leyenda: /n: nacional, /r: republicano, RCH: Robledo de Chavela, SMA: Sta. Ma . de la Alameda, VMO: Valdemaqueda.

Figure 5. Types of shooting positions. A: Circular (Matiazo/n, $\left.R C H^{*}\right)$. B: In a corridor (Valdemaqueda 1/n, VMQ). C: In a false T (Peña Mocha Baja/n, SMA). D: In T with a parapet (Ciudad Prohibida/n, SMA). E: In U (Muro Largo/r, SMA). F: In C (Muro Largo/r, SMA). G) General view

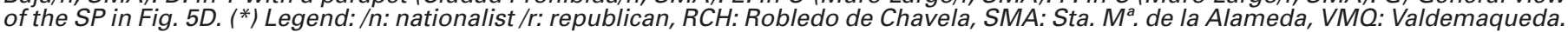

Acorde con el alto porcentaje de elementos relacionados con la potencia de fuego, observamos que, prácticamente la totalidad del mismo $(99,4 \%)$, se corresponde con emplazamientos de armas de tiro tenso, preferentemente: puestos de tirador (PT's), fortines y nidos de ametralladora (N/A).

\section{Puestos de tirador (PT's) (301)}

Son obras sencillas, en la mayoría de los casos, y vienen a resolver necesidades inmediatas del soldado para proteger su integridad en el combate, por ello se incluyen en el grupo denominado "Emplazamiento de armas individuales". Tanto su morfología como el tipo de construcción cambia mucho de un lugar a otro, aunque suelen reproducirse tendencias en función de los CoDe's donde se encuentran. El sistema constructivo varía entre excavados y construidos y, entre estos últimos, pueden ser de mampostería a hueso o con mortero de cemento; respecto a la morfología es muy variable, habiendo encontrado: circulares, semicirculares, cuadrangulares, rectangulares, en pasillo, en $U$, en T, en falsa $T$, en $L$, en $C$. En el bando republicano los más abundantes son los circulares y, mayoritariamente, realizados en mampostería en seco; mientras que entre los nacionales los más extendidos son los denominados en T, de mampostería con mortero de cemento, que representan un estado bastante evolucionado de la construcción, pues contaban con un escalón, en el fondo del pozo, que les libraba de las aguas de escorrentía y de las humedades y también, a veces, presentaban un parapeto con aspilleras, lo que les facilitaba el tiro (Fig. 5). Se trata de obras estandarizadas que siguen modelos empleados por las divisiones 71 y 72 .

\section{Nidos de ametralladora (N/A's) (74)}

Posiblemente sea la obra defensiva más conocida de todos. Su presencia en el paisaje siempre aporta una sensación de interés y curiosidad sobre lo que significa y el contexto en que se generó.

Por su potencia de fuego y capacidad intimidatoria eran las construcciones más cuidadas, y queridas, dentro de una posición. La elección de sus emplazamientos, para maximizar su potencia de fuego, aprovechar los campos de tiro, elegir una buena rasancia y diseñar un buen esquema de cruce del tiro con otras armas automáticas propias, eran una de las decisiones más difíciles y arriesgadas del responsable al mando de la unidad allí desplegada, pues una mala elección del emplazamiento de las armas automáticas podía suponer la pérdida de la posición.

La morfología de estas obras era muy diversa, las había de forma: circular, cuadrada, rectangular, pentagonal, hexagonal, poligonal, en $\mathrm{D}$, en igloo, aunque las formas más comunes eran las cuadrangulares y las rectangulares. Respecto a su sistema constructivo, 

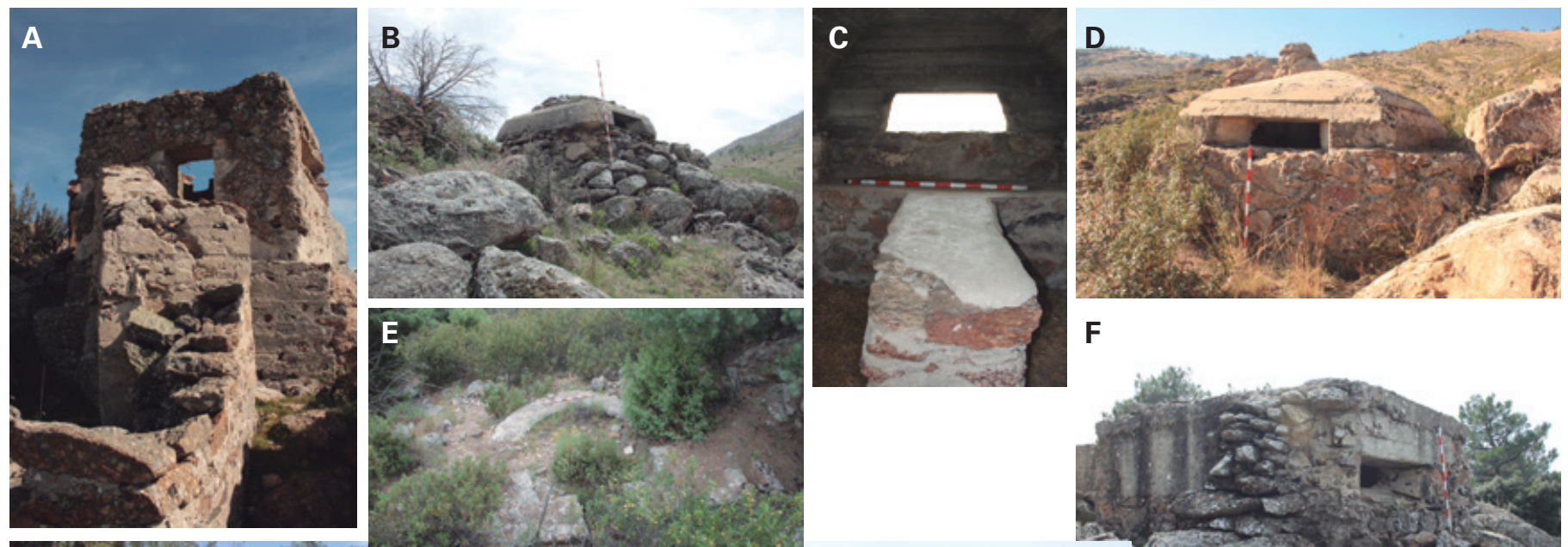

\section{$\mathbf{F}$}
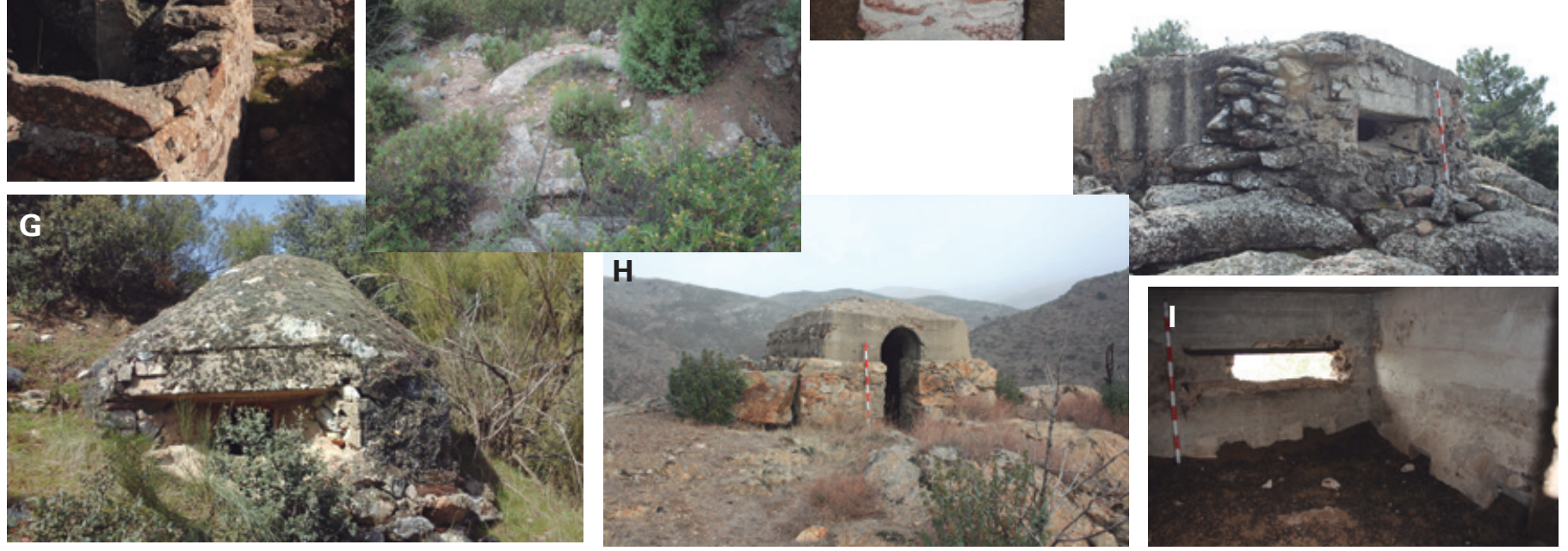

Figura 6. Nidos de ametralladora. A: Cuadrangular y hormigonado, con dos troneras y dos aspilleras (Ciudad Prohibida/n, SMA). B: Cuadrangular, de mampostería con mortero de cemento y techo hormigonado y camuflado con rocas incorporadas al fraguado, presenta una tronera frontal (Peña Mocha Baja/n, SMA). C: Interior del nido anterior, presentando el banco para apoyar el arma automática. D: Cuadrangular, de mampostería con mortero de cemento y techo hormigonado, presenta una tronera frontal (Valdemaqueda 4/n, VMQ). E: Nido en D y hormigón en toda la estructura, con dos troneras (Muro Largo/r, SMA). F: Rectangular, de mampostería con mortero de cemento y techo hormigonado y camuflado, y una tronera frontal (Ciudad Prohibida/n, SMA). G: En igloo y estructura de hormigón, cuenta con dos troneras (Estación Primo de Rivera/n, RCH). H: Rectangular, de mampostería con mortero de cemento y cúpula hormigonada (Valdemaqueda $2 / n$, VMQ). I: Interior del N/A de la Fig. 5F, donde se aprecian las cavi dades para anclar los patines de la ametralladora Hotchkiss, por debajo de la tronera frontal.

Figure 6. Types of machine-gun nests. A: Square and concreted, with two slits and two loopholes (Ciudad Prohibida/n, SMA). B: Quadrangular, made of masonry with cement mortar and a concrete roof, camouflaged with rocks incorporated in the setting and with a front slit (Peña Mocha Baja/n, SMA). C: Interior of the previous nest, presenting the bench to support the automatic weapon. D: Quadrangular, made of masonry with cement mortar and concrete roof, it has a front slit (Valdemaqueda 4/n, VMQ). E: D-shaped nest with two loopholes and all its structure concreted (Muro Largo/r, SMA). F: Rectangular, made of masonry with cement mortar and a concrete and camouflaged roof and a front pocket (Ciudad Prohibida/n SMA). G: An igloo and concrete structure, it has two loopholes (Estación Primo de Rivera/n RCH). H: Rectangular, made of masonry with cement mortar and concrete dome (Valdemaqueda 2/n, VMQ). I: Interior of the MG/N in Fig. $5 F$, where the cavities for anchoring the skids of the Hotchkiss machine gun can be seen, below the front slit.

aunque existen nidos de mampostería a hueso, la importancia del elemento defensivo era tal que atraía la mayoría del fuego enemigo, con el fin de inutilizarlo y favorecer el ataque; sí además el enemigo disponía de artillería, las posibilidades de destruirlo con un impacto directo eran muy elevadas, de ahí que a menudo tuviesen blindaje; bien en toda su estructura o, por lo menos, en el techo. Por lo cual la mayoría de ellas se han construido con mampostería con mortero de cemento y el techo blindado con hormigón en masa o armado, mediante traviesas metálicas, piquetas o cualquier otro elemento férreo que añadir a la estructura para reforzarla al máximo; no obstante, hay N/A's que presentan hormigón en toda su estructura, aunque, en la mayoría de los casos, corresponden a obras muy tardías, construidas en los meses finales de la guerra (Fig. 6).

Otra condición que se cuidaba mucho en todas las construcciones defensivas, desde ambos bandos, era el tratar de ocultarlas; por ello se pretendía mimetizar la obra con el paisaje para evitar su localización por los observatorios o por la aviación enemiga. Esta obsesión por la ocultación era máxima respecto a los emplazamientos de las armas automáticas propias, aunque estuviesen construidas con hormigón. Para ello se solía incluir mampostería irregular en el techo del nido antes del fraguado, con lo que las rocas aportaban a la construcción una morfología y una coloración que permitía hacerla pasar más inadvertida, preservándola así del fuego artillero enemigo. 

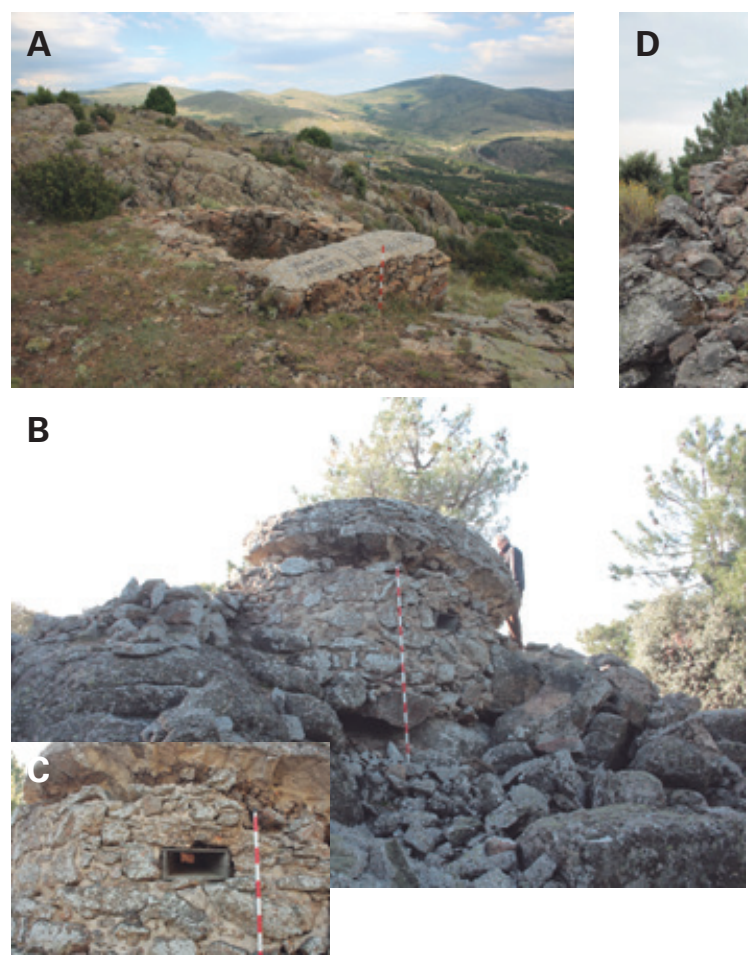
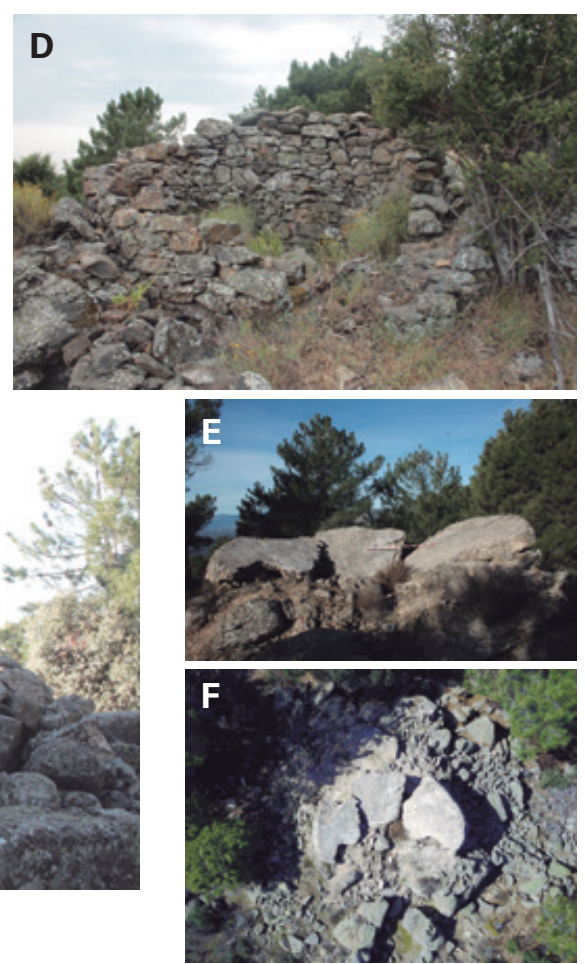
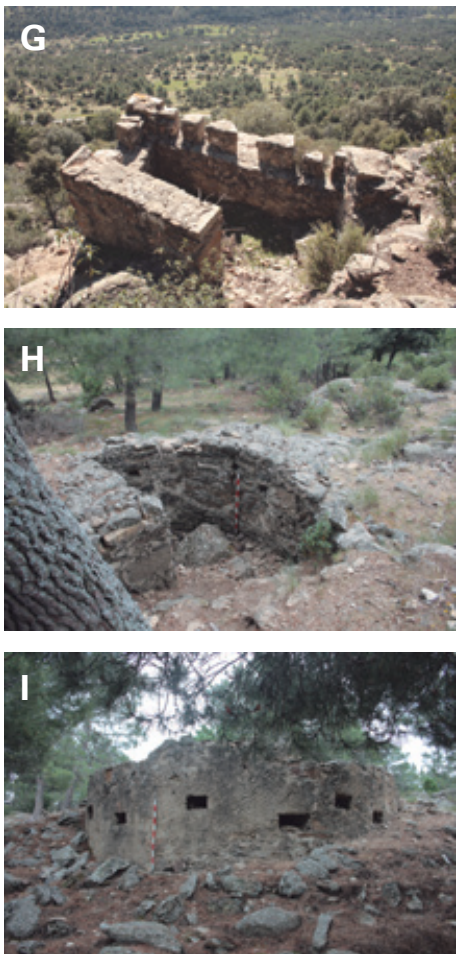

Figura 7. Fortines. A: Fortín rectangular con aspilleras para los fusileros y techo reforzado con hormigón, sus dimensiones son $4,70 \times 2,90$ $\mathrm{m}$ (Navalespino/r, SMA). B: Restos de un fortín circular, de mampostería a hueso y $2,70 \mathrm{~m}$ de $\varnothing$ interior (Robledillo Sur/r, RCH). C: Fortín $5^{\circ}$ $\mathrm{Rgt}^{\circ}$. en $\mathrm{D}$, de mampostería de gneis y ladrillo con mortero de cemento y techo blindado plano de hormigón, presenta dos troneras y tres aspilleras y $4,70 \mathrm{~m}$ de $\varnothing$ interior (Fortines de la Muerte/r, SMA). D: Detalle del encofrado de madera de una de las troneras del anterior fortín. E: Restos del techo blindado del fortín de la Fig. 6C tras su voladura. F: Detalle azimutal (mediante dron) de los anteriores restos. G: Fortín $5^{\circ} \mathrm{Rgt}^{\circ}$. rectangular, mampostería con mortero de cemento, presenta dos troneras y cuatro aspilleras. Sus dimensiones son 4,75x3 m (Robledillo Sur/r, RCH). H: Fortín $5^{\circ} \mathrm{Rgt}^{\circ}$. en D, con una tronera y dos aspilleras y 3,50 m de flecha (Fortines de la Muerte/r, SMA). I: Vista frontal de un fortín $5^{\circ} \mathrm{Rgt}^{\circ}$. donde se le aprecian los niveles inferiores de troneras y los superiores de aspilleras (Fortines de la Muerte/r, SMA).

Figure 7. Types of fortresses. A: Rectangular fort with loopholes for the riflemen and reinforced concrete roof, its dimensions are $4.70 \times 2.90$ $m$ (Navalespino/r, SMA). B: Remains of a circular dry masonry fortress with an interior diameter of $2.70 \mathrm{~m}$ (Robledillo Sur/r, RCH). C: Circular fortress of $5^{\text {th }}$ Regiment, made of gneiss and brick masonry with cement mortar and flat armoured concrete roof, it has two slits and three loopholes and $4.70 \mathrm{~m}$ of interior Ø (Fortines de la Muerte/r, SMA). D: Detail of the wooden formwork of one of the slits of the previous fort. E: Remains of the armoured roof of the fort in Fig. 6C after it was blown up. F: Azimuthal detail (by drone) of the previous remains. G: Rectangular fort of the $5^{\text {th }}$ Regiment, built with masonry and cement mortar. It has two slits and four loopholes and its dimensions are $4.75 \times 3 \mathrm{~m}$ (Robledillo Sur/r, RCH). H: Fortress of the $5^{\text {th }}$ Regiment with D-shape, with a slit and two loopholes and a $3.50 \mathrm{~m}$ arrow (Fortines de la Muerte/r, SMA). I: Frontal view of a $5^{\text {th }}$ Regiment fortress, with the lower levels of slits and the upper levels of loopholes (Fortines de la Muerte/r, SMA).

\section{Fortines(96)}

El término fortín es, posiblemente, uno de los más inconcretos o difíciles de definir debido a su utilización para elementos defensivos diferentes. Creemos que la definición que Schnell Quiertant y de Arnaiz Seco (2019) proponen: "Obras excavadas con parapetos de piedra en seco o blindajes de tierra soportada por rollizos, aunque también se denominan con esta palabra a otras obras construidas de fábrica", siempre relacionada con pocos defensores, se ajusta bastante a la realidad; pero consideramos que es importante reseñar una característica que entendemos es definitoria de un fortín, la posibilidad de coexistencia de armas individuales con automáticas, de ahí la denominación de "Emplazamiento de armas mixtas" que utilizamos en laTabla 1. Su morfología es diversa: cir- cular, semicircular, cuadrangular, rectangular, pentagonal, aunque en el frente republicano la forma más extendida es la circular y en el lado nacional la cuadrangular. Donde sí que hay coincidencia entre los dos bandos es en el sistema constructivo empleado, la mampostería a hueso.

Dentro de este grupo queremos señalar dos tipologías muy particulares, una de cada bando, que demuestran el grado de especialización al que se llegó a lo largo de la contienda, en un caso en los inicios de la misma y en el otro en su etapa final; nos referimos a los que hemos denominado Fortines tipo: $5^{\circ}$ Regimiento y blockhaus.

Los fortines tipo $5^{\circ}$ Regimiento reciben ese nombre porque se construyeron en los primeros meses de la guerra en el frente cubierto por el $5^{\circ}$ Regimiento de Milicias Populares, organizado por el Partido Co- 
munista. Esta unidad fue el vivero de los principales dirigentes militares del ejército republicano: Juan GuiIloto “Modesto", Enrique Líster, Valentín González “EI Campesino" y Manuel Tagüeña. Fue la única unidad republicana que, en los primeros meses del conflicto bélico, actuó de una forma acorde a lo que se esperaba de una unidad combatiente entendiendo, desde el primer momento, que para poder hacer la revolución primero había que ganar la guerra, y no al revés. Esta Unidad, en los seis meses que tuvo de existencia hasta su disolución e integración en el nuevo Ejército Popular de la República se dedicó, además de luchar en primera línea, a coordinar, en la retaguardia, una serie de actividades culturales y sociales: campañas de alfabetización en el frente, bibliotecas circulantes, "guerrillas teatrales", etc.; e, incluso, utilizó su órgano oficial, "Milicia popular: Diario del $5^{\circ}$ Regimiento de Milicias Populares" para instruir a su lectores, combatientes, en el manejo de las armas, así como en nociones de táctica militar y estrategia en el combate. Por ello no es de extrañar que esa preocupación por el conocimiento y utilización de los conceptos militares se aprovechasen en la construcción de un tipo de fortín con unas características muy concretas y, casi constantes, en todos los ejemplos localizados. Se construían con mampostería enlucida con mortero de cemento $y$, en muchos casos, proporcionándole un blindaje al techo, con mejor (traviesas metálicas y hormigón) o peor calidad (troncos y mampostería con cemento) en función de los medios disponibles. Morfológicamente eran mayoritarios los de forma circular, con diámetros que oscilaban entre los $1,30 \mathrm{~m}$ (para poco más de 2 o 3 hombres) hasta los $7 \mathrm{~m}$ o más; aunque también hemos localizado fortines de este tipo de forma cuadrangular, aunque en menor número que los circulares (Schnell Quiertant y Baltuille Martín, 2017).

En la zona de trabajo, la mayoría de estos fortines presentan tanto aspilleras, para armas individuales (fusiles), como troneras, para armas automáticas (ametralladoras ligeras o subfusiles). Las aspilleras se encuentran en la parte superior del muro del fortín, para facilitar el disparo de pie al fusilero, mientras que las troneras aparecen ubicadas en la zona media de los muros, para facilitar la posición sentada que conlleva el uso de armas automáticas (Fig. 7).

El otro tipo particular de fortín, localizado en la zona de trabajo, es el denominado blockhaus. La denominación es de origen alemán, "casa de bloques" o "casa de "troncos", y se empleó castellanizada como "blocao" por el ejército español, tanto en las campañas de Cuba como de África. En el caso de Cuba se trataba de pequeños fortines, de tierra y troncos, que preservaban las trochas, para evitar las incursiones de los "mambises". En las campañas africanas, se cons- truían con elementos prefabricados traídos desde la retaguardia, al no contar con elementos constructivos las aisladas posiciones que se iban ocupando.

Los ingenieros de la 71 división nacional utilizaron ese mismo término en un modelo de fortín que diseñaron a finales de 1938 para defender nudos de comunicaciones en retaguardia, aprobándose la construcción de un total de dieciséis. En diciembre de 1938 se inicia la construcción de siete de ellos y en los últimos días del año ya se habían excavado sus emplazamientos (Castellano, 2004). El único acabado de la serie fue el blockhaus $\mathrm{n}^{\circ} .13$ de Colmenar del Arroyo. Su gemelo, al otro lado de la carretera no se concluyó y desapareció con la construcción de un chalet.

En el proyecto se han localizado las excavaciones previas de otros dos, los números 7 y 8 . La finalización de la guerra paralizó las obras de estos fortines, que nunca llegaron a terminarse.

\section{Alojamientos de la tropa (292)}

Los alojamientos para la tropa se han dividido en tres tipos: chabola, barracón y catenaria. Salvo excepciones, cada uno representa un mayor nivel tecnológico y de confortabilidad que el que le precede. Aparte $y$, para tratar de poner un cierto orden en la literatura científica sobre la Guerra Civil Española sobre la utilización indistinta que se hace, a menudo, de los términos chabola y barracón, hemos buscado la definición que la Real Academia Española de la Lengua (RAE) da al término barracón: "Edificio rectangular de una planta, construido por lo general con materiales ligeros, para albergar tropas, prisioneros u otros grupos de personas". La definición es meridianamente clara, luego entonces el siguiente paso es analizar el término rectángulo $y$, de nuevo, es la RAE quien resuelve cualquier duda sobre la palabra rectángulo: "Paralelogramo que tiene los cuatro ángulos rectos y los lados contiguos desiguales". Por ello, en este trabajo, hemos definido un "índice de rectangularidad", longitud/anchura $\geq 1,35$, que permita clasificar los barracones y las chabolas. Todas las construcciones que alcancen o superen ese coeficiente serán definidas como barracón y se les asignará una forma rectangular, y aqueIlas que no lo alcancen serán citadas como chabolas y se les adscribirá una forma cuadrangular, salvo excepciones concretas (circulares, poligonales, asimétricas), aunque estas son casi testimoniales.

Las chabolas, pues, son viviendas cuadrangulares, de dimensiones medias de $4 \times 3,30 \mathrm{~m}$, algo mayores las nacionales $(4,35 \times 3,40 \mathrm{~m})$ y algo menores las republicanas $(3,70 \times 3,20 \mathrm{~m})$; construidas, mayoritariamente, en mampostería en seco y que daban cobijo a una media 

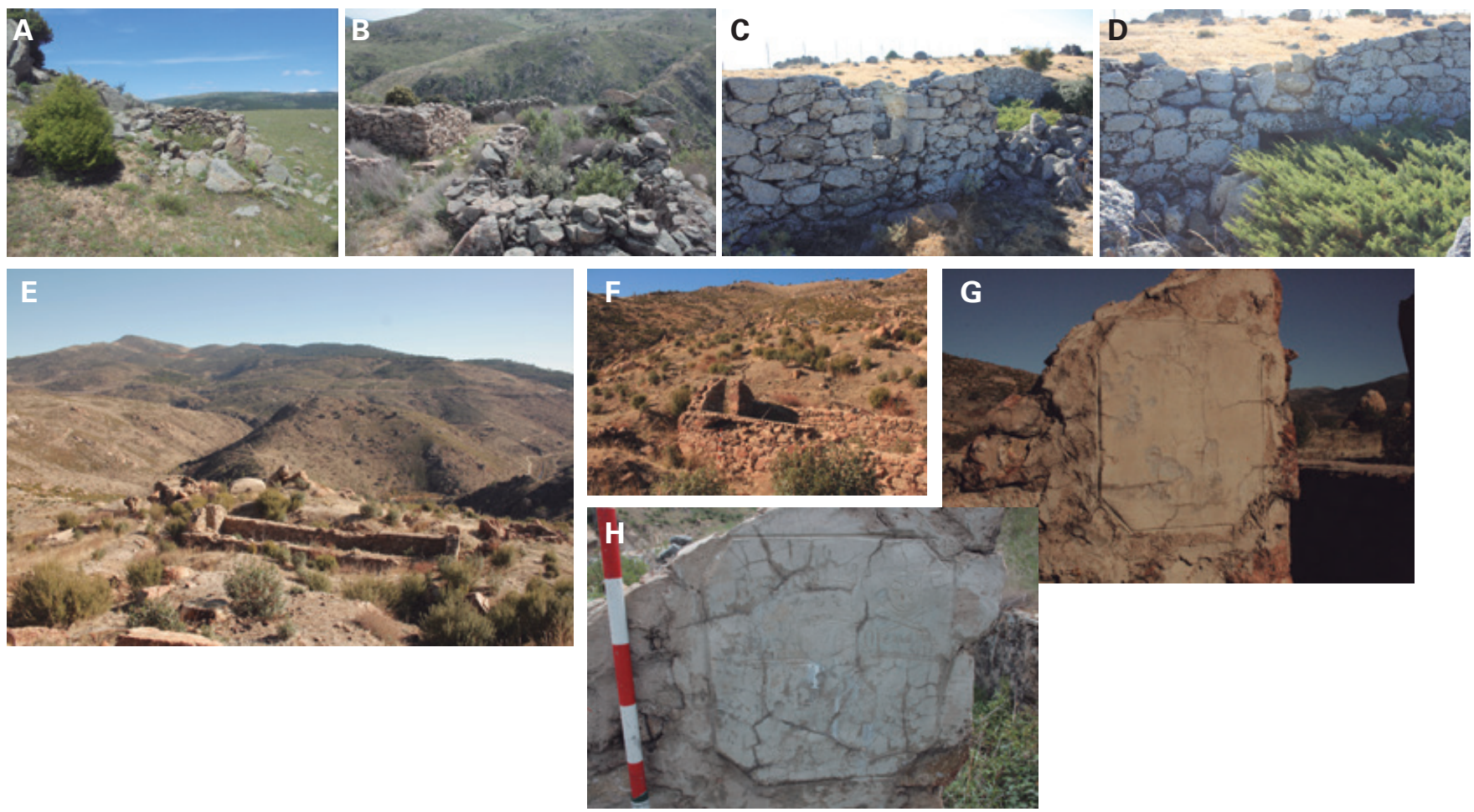

Figura 8. Chabolas y barracones. A: Restos de chabola de mampostería a hueso (Matalahoya/r, SMA). B: Chabolas, en diferentes estados de conservación (Posición Pilón/n, SMA). C: Barracón de mampostería a hueso, con ventana adintelada y puerta abiertas hacia el NE (Valdemadera/r, SMA). D: Chimenea francesa, en la pared SO, del barracón anterior, E: Barracón de un conjunto defensivo estandarizado. Obsérvese, por detrás del barracón y hacia el fondo de la foto, un N/A con cúpula de hormigón, igual que el de la Fig. 5H (Valdemaqueda 4/n, VMO). F: Detalle de la foto anterior donde se observa, en la pared en primer plano, la inserción de la chapa corrugada del techo (desaparecido) sobre el mampuesto. G: Placa de cemento de la fachada SO del anterior barracón, con el castillo del arma de Ingenieros y debajo la inscripción "27 Cía". H: Placa de cemento en el dintel izquierdo del barracón central, con el escudo de Ingenieros y la inscripción, "Bon 291. Sección Ofensiva. $27 \mathrm{CIA}^{\prime \prime}$ (Valdemaqueda 1/n, VMQ).

Figure 8. Types of shacks and barracks. A: Remains of a dry masonry shack (Matalahoya/r, SMA). B: Shacks, in different states of conservation (Posición Pilón/n, SMA). C: Dry masonry barrack, with lintelled window and door open to the NE (Valdemadera/r. SMA). D: French chimney, in the SW wall, of the previous barrack, E: Barrack of a standardized defensive set. Note, behind the barracks and towards the background of the photo, a concrete dome MG/N, as in Fig. $5 \mathrm{H}$ (Valdemaqueda 4/n, VMQ). F: Detail of the previous photo where you can see, on the wall in the foreground the insertion of the corrugated roof plate (missing) over the masonry wall. G: Cement plate of the SW facade of the previous barrack, with the Engineer's Gun Castle and below the inscription "27 Cía". H: Cement plate, located on the left lintel of the central barracks, with the shield of the Engineer's Armoury and the inscription, "Bon 291. Offensive Section. 27 CIA." (Valdemaqueda 1/n, VMQ).

de 4 hombres. La elección de este sistema constructivo se debe a la urgencia de dotar de refugio para pernoctar la tropa desde el primer momento de la ocupación del terreno, para lo que se utilizaba el material más accesible del que cada unidad disponía, el mampuesto del roquedo próximo. La preponderancia de la mampostería a hueso sobre la que llevaba mortero es muy apreciable, $86,6 \%$ y $17,4 \%$ respectivamente; pero si lo vemos a nivel de contendientes, la diferencia se acentúa. En el bando republicano alcanzaba un total del 94 $\%$, mientras que el nacional descendía al 71,4\%.

Solían disponer de una sola entrada y una ventana para la aireación y sus tejados, normalmente vertían a una sola agua. En algunos casos se han localizado ciertas particularidades en la vivienda, con el fin de dotarla de una mayor confortabilidad, tal es el caso de las chimeneas; aunque por la ubicación de la chabo- la, su tamaño y esas mejoras encontradas, nos hace pensar en el alojamiento de algún oficial o lugar de reunión de los mandos de esa unidad, aunque sea a nivel de sección, lo que no nos permite considerarlos puestos de mando (PC's) reales.

El siguiente grado en avance tecnológico lo representan los barracones, que ya hemos visto que por definición presentan morfología rectangular. En el bando nacional su implantación está más extendida que en el republicano, y las dimensiones de sus barracones arrojan una distribución bimodal clara en función del índice de rectangularidad $2 \leq 1 / a \geq 2$, que representan el 63,6 $\%$ y el $36,4 \%$, respectivamente $y$, cuyas dimensiones son: $4,80 \times 3,10$ y $9,40 \times 3,25 \mathrm{~m}$. También se observa, ya, una representación más elevada del uso de mortero para consolidar los muros y evitar las inclemencias. En el grupo de los barracones de menor tamaño, el 31,4\% 

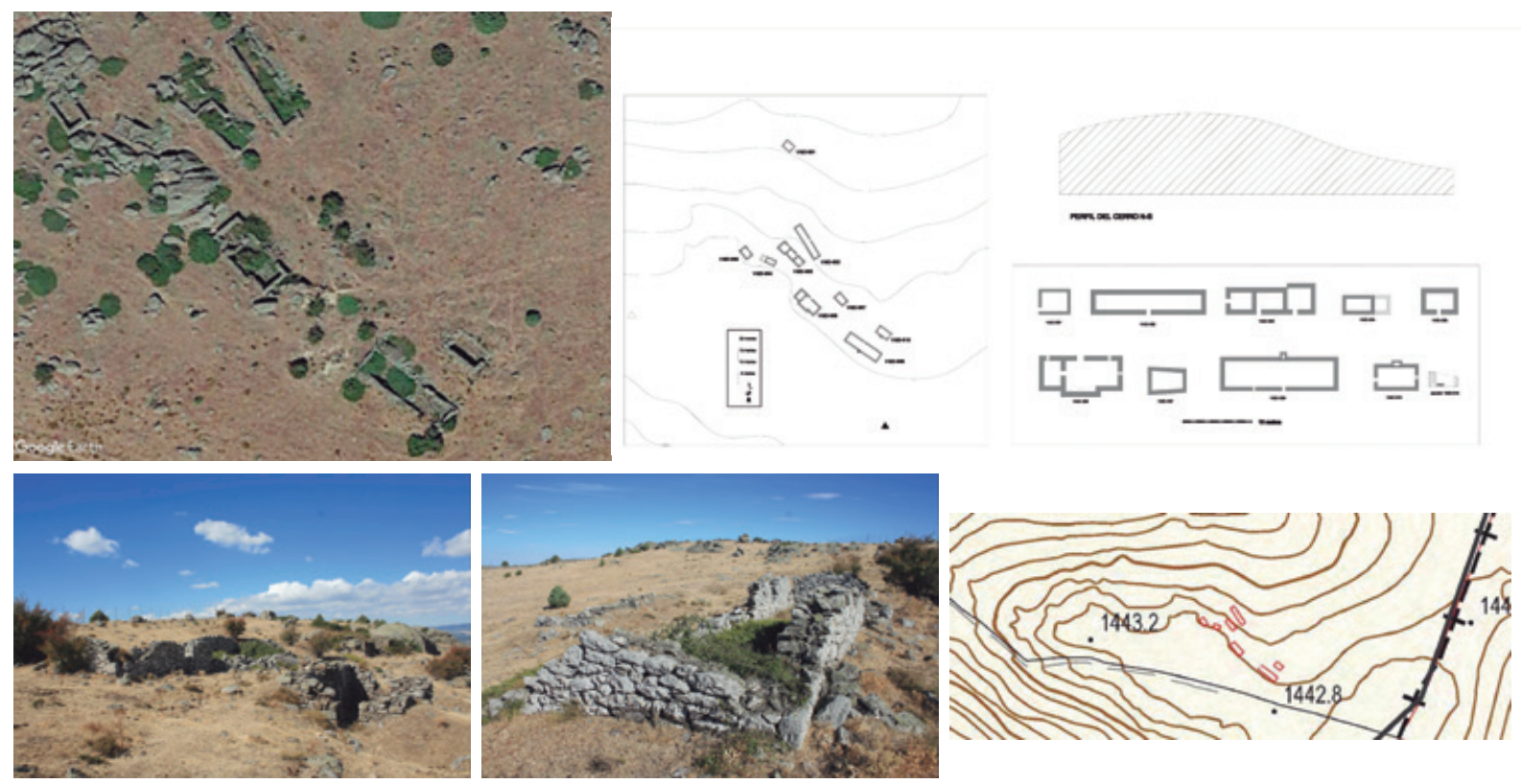

Proyecto Paisaje, Geologia y Arquitectura militar.

Las construcciones defensivas del Frente de Madrid (1936-1939)
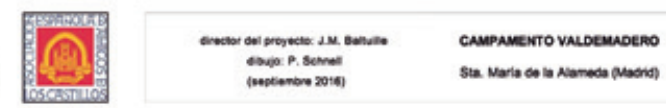

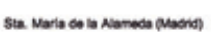

Figura 9. Imágenes y esquemas del campamento republicano de Valdemadera (Santa María de la Alameda, Madrid).

Figure 9. Images and diagrams of the Republican military camp of Valdemadera (Santa María de la Alameda, Madrid).

está construido en mampostería enlucida con mortero, porcentaje que asciende en los de mayor tamaño hasta el $45 \%$. Mención particular hay que hacer, en el bando nacional, a una serie de barracones que forman parte de una serie de obras estandarizadas (barracones, N/A's cuadrados con techo de hormigón, PT's en T) que conformaron una serie de CoDe's construidos a fínales de la guerra. Los barracones, uno o dos (el segundo era menor), solían tener dimensiones entre los 10-12 m de largo y 3-3,20 $m$ de ancho el mayor y eran de mampostería con mortero de cemento y bóveda de medio cañón, sujeta por chapa corrugada, siempre desaparecida. Junto a la entrada solían presentar una placa de cemento con una inscripción (generalmente referente a la unidad que los construye) (Fig. 8).

En el bando republicano las cosas son parecidas, pero no iguales. Existe también una distribución bimodal respecto al índice $2 \leq 1 / a \geq 2$, representadas por el $52,80 \%$ y el $47,20 \%$, respectivamente, es decir, disminuye el número de barracones pequeños y aumentan los de mayor tamaño; aunque las dimensiones medias: $4,55 \times 2,80$ y $8,40 \times 3,05 \mathrm{~m}$ son, ligeramente, menores. Otra diferencia importante entre ambos bandos, es la escasa presencia de mampostería con mortero en los barracones republicanos, donde repre- sentan el 10,50 \% en el grupo de los pequeños y del 6 $\%$ en el de los de mayor tamaño.

Podían ser utilizados como dormitorios o como almacenes o, a veces, como pequeños dispensarios o botiquines de campaña. Solían tener más de una puerta y de 2 a 4 ventanas y, generalmente, su interior estaba dividido en varias piezas y el tejado solía estar construido a dos aguas. A veces y debido a su alta concentración en una pequeña superficie, llegaba a constituir verdaderos campamentos, como ocurre en el Cerro de Valdemadera y en El Robledillo en la zona republicana (Fig. 9).

Finalmente, y en el nivel más alto de la tecnología de la construcción, aparecen las catenarias. Sólo se localizan en el bando nacional y, más concretamente, en las divisiones desplegadas a lo largo de las sierras del norte de Madrid, divisiones 71 y 72 . La catenaria, cuya definición en geometría y arquitectura es "la curva cuyo trazado sigue la forma que adquiere una cadena o cuerda, de densidad uniforme, y perfectamente flexible sujeta por sus dos extremos y que se encuentra sometida, únicamente, a las fuerzas de la gravedad", se denomina a aquella construcción, cuya bóveda se asemeja a la "curva catenaria" y cuyo sistema constructivo consistía en una fábrica de ladrillo, enlucido con yeso o cemento o, a veces, se llega hasta el encofrado de 

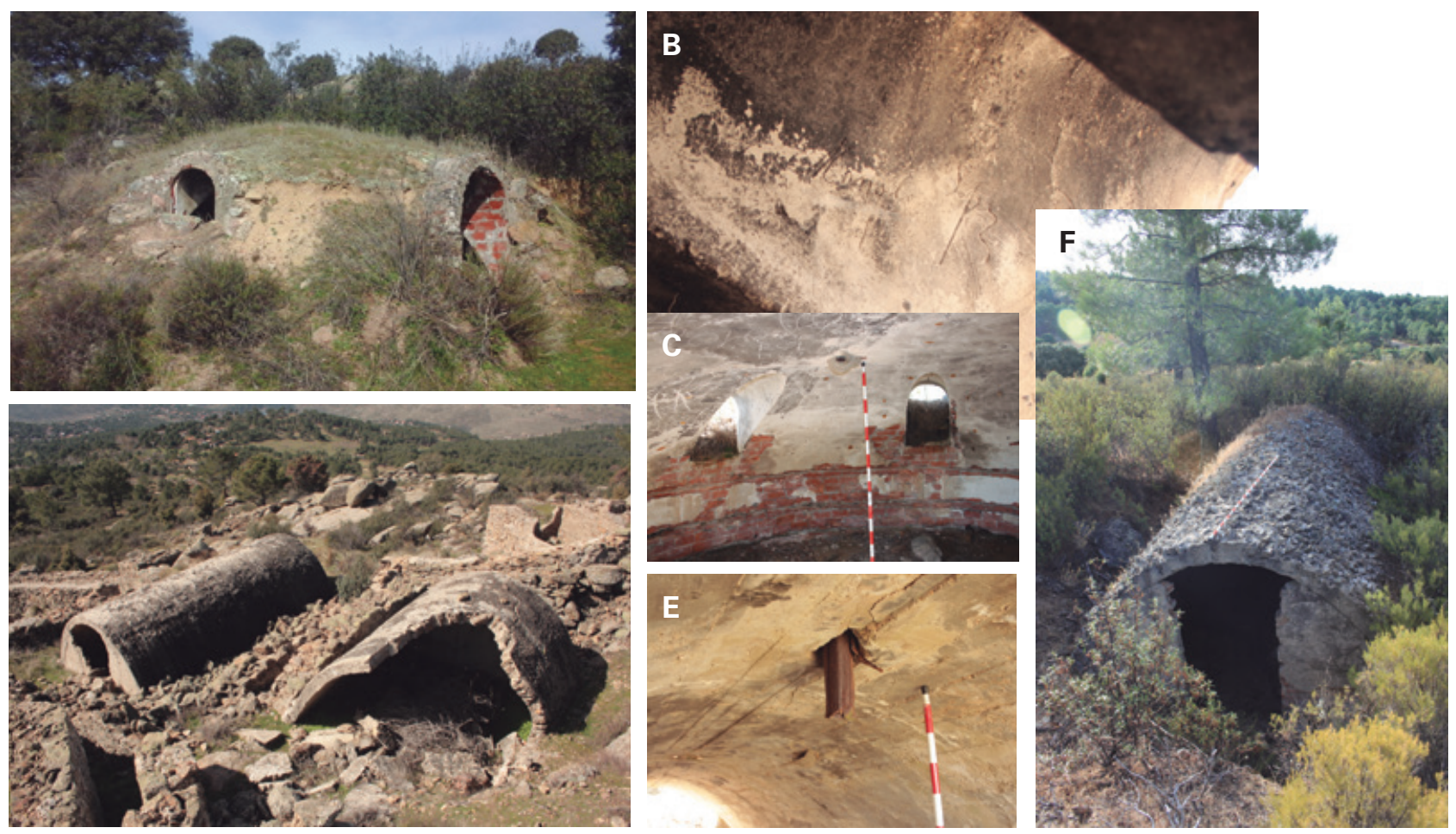

Figura 10. Catenarias. A: Catenaria circular o discoidal, de fábrica de ladrillo con enlucido de yeso y una puerta abovedada, orientada hacia el $\mathrm{E}$ y dos ventanas, también abovedadas, abiertas al S y al O (Aviñón/n, RCH). B: Grafiti en la anterior catenaria: "Manolo López Díaz". C: Detalle del interior de una catenaria circular (Matiazo/n, RCH). D: Catenarias rectangular y cuadrangular, respectivamente, con restos de alquitrán en el techo para su impermeabilización y huecos para la chimenea de la estufa, dos en la rectangular y uno en la cuadrada (Ciudad Prohibida/n, SMA). E: Detalle del tubo original de la chimenea encastrado en el techo de la catenaria 9D. F: Catenaria rectangular de encofrado de hormigón (La Corbera/n, SMA).

Figure 10. Types of catenaries. A: Circular or disc-shaped catenary, made of brick with plaster and a vaulted door, facing east, and two windows, also vaulted, open to the south and west (Avignon/n, RCH). B: Graffiti on the previous catenary: "Manolo López Díaz". C: Interior of catenary 9A. D: Rectangular and quadrangular catenaries, respectively, with remains of tar on the roof for waterproofing and holes for the stove chimney, two holes on the rectangular and one on the square (Ciudad Prohibida/n, SMA). E: Detail of the original chimney pipe embedded in the roof of the 9D catenary. F: Rectangular catenary of concrete formwork (La Corbera/n, SMA).

hormigón. Su morfología mayoritaria es la rectangular, aunque también se encuentran redondas o discoidales y, en menor proporción, cuadradas.

La obra solía presentar, o bien una puerta en una de las fachadas y una ventana en la opuesta o bien dos puertas, una en cada fachada y una pequeña ventana junto a la puerta principal. El techo estaba alquitranado, para evitar las humedades producidas por la lluvia y era muy corriente el dotarlas de sistemas de calefacción, consistente en estufas de hierro con una chimenea metálica encastrada en el techo (Fig. 10), glorias bajo el suelo o chimeneas francesas. Su utilidad era diversa: alojamiento, PC, botiquín, almacén, etc.

\section{Observatorios (16)}

En el presente trabajo constituyen elementos minoritarios, debido a su limitada presencia en el teatro de operaciones, respecto a otras construcciones defensivas; al tratarse de elementos muy específicos y de una utilidad muy concreta, observar los movimientos enemigos y prever sus acciones o dirigir el tiro propio artillero o el de las armas automáticas. A veces suelen dar servicio a varios conjuntos defensivos, si estos mantienen una cierta proximidad.

Presentan formas circulares, cuadrangulares o rectangulares y suelen estar blindados, generalmente con hormigón, por ser puntos de gran atracción del fuego enemigo, aunque también se encuentran observatorios construidos de mampostería en seco o con mortero de cemento (Fig. 11).

\section{Conclusiones}

Este estudio nos ha permitido desarrollar una metodología específica de trabajo, que en esta publicación se expone, a la vez que se presentan los primeros resultados obtenidos, documentando fortificaciones y organizaciones defensivas inéditas. 


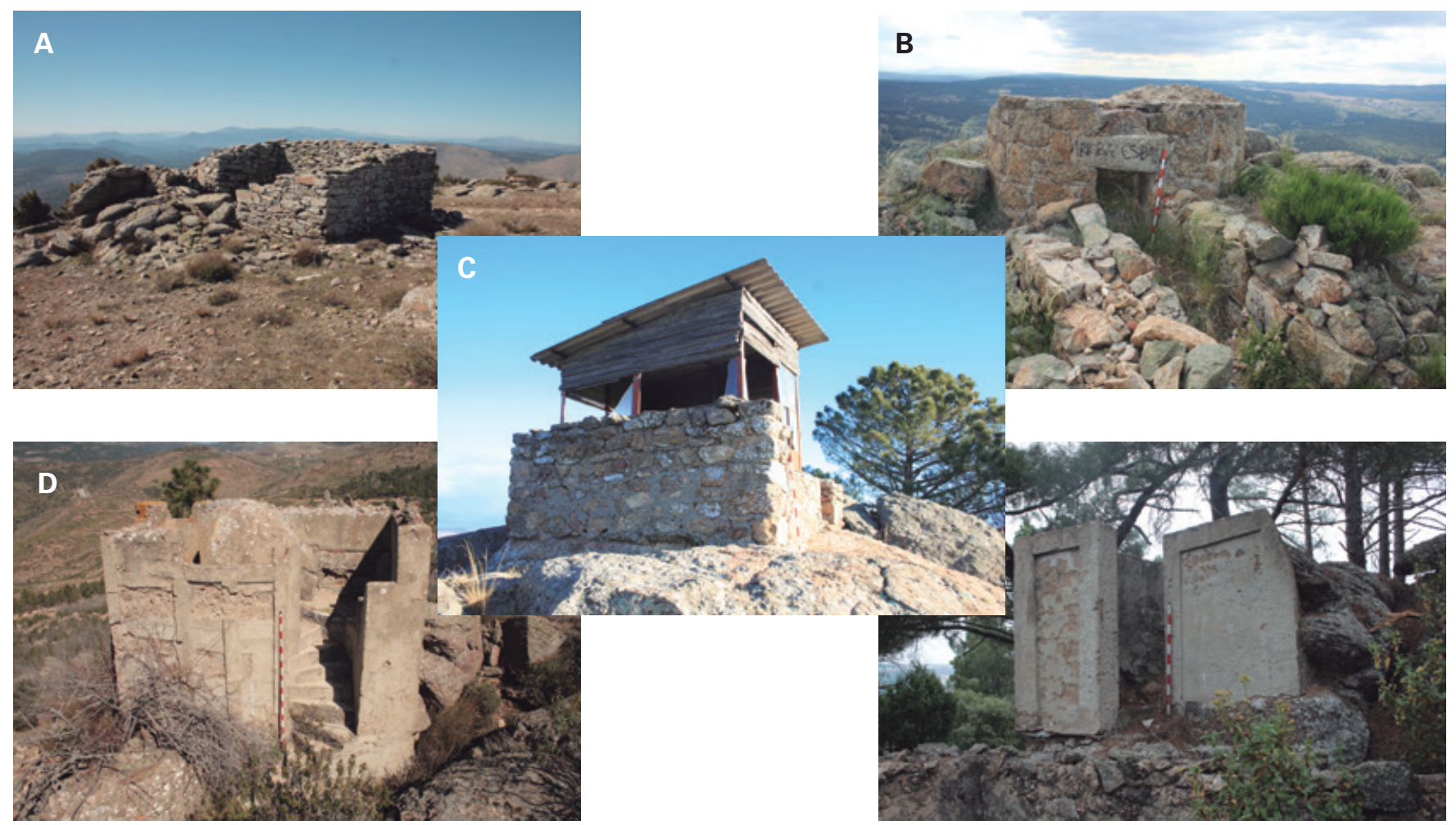

Figura 11. Observatorios. A: Cuadrangular de mampostería a hueso, con una repisa de piedra en una de las esquinas y puerta abierta al E. Conecta, visualmente, con el Cerro de San Benito (Robledillo/r, RCH). B: Obra circular $(2,30 \mathrm{~m}$ de $\varnothing$ ) de sillares de granito con cemento, acceso trasero a trinchera de fábrica y puerta con dintel. Vestigios de techo blindado del estilo de los Fortines del $5^{\circ}$ Reg. Presenta huellas de actos vandálicos (Navalespino/r, SMA). C: Obra rectangular en alto, sobre una roca y construido con mampostería y mortero de cemento. Se accede por una escalera con peldaños entre la roca. Está transformado en una caseta de vigilancia antincendios (La Atalaya/n, VMO). D: Construcción rectangular de hormigón, levantado sobre la roca, con escalera de caracol y bancos de fábrica (Posición Casilla/n, SMA). E: Observatorio cuadrangular de fábrica, que aprovecha los afloramientos de bolos de gneis existentes y presenta un escalón de acceso. Los lienzos del exterior están decorados con reborde (Ciudad Prohibida Norte/n, SMA).

Figure 11. Types of observatories. A: Quadrangular dry masonry observatory, with a stone shelf in one of the corners and an open door to the E. It visually connects with Cerro de San Benito (Robledillo/r, RCH). B: Circular work (2,30 m of Ø) of granite ashlars with cement, rear access to factory trench and door with lintel. Vestiges of the armoured ceiling of the style of the forts of the $5^{\text {th }}$ Regiment. It presents traces of vandalism (Navalespino/r, SMA). C: Rectangular building on top of a rock, built with masonry and cement mortar. Access is via a staircase with steps between the rocks. It has been converted into a fire watch house (La Atalaya/n, VMQ). D: Rectangular construction made of concrete, raised on the rock, with a spiral staircase and benches (Posición Casilla/n, SMA). E: Quadrangular factory observatory, which takes advantage of the existing gneiss outcrops and has an access step. The exterior panels are decorated with a border (Ciudad Prohibida Norte / $n$, SMA).

Alguna de las cifras que conviene recordar, como conclusiones del trabajo, son:

$1^{\circ}$. Estudio de una superficie de $132 \mathrm{~km}^{2}$, en los términos municipales de Robledo de Chavela, Santa María de la Alameda y Valdemaqueda, en la Comunidad de Madrid.

$2^{\circ}$. Determinación de 1.016 construcciones defensivas, de diferente índole: alojamientos de tropa, emplazamientos de armas automáticas, fortines, observatorios, puestos de tirador, parapetos y trincheras, englobadas en un total de 54 posiciones o conjuntos defensivos (CoDe's), 29 republicanos y 35 nacionales (Fig. 3); varias de las cuales, junto con todos sus elementos constructivos, son documentadas y estudiadas por primera vez, gracias a este proyecto.

$3^{\circ}$. Descubrimiento y divulgación de siete CoDe's, en el frente de la 71 División nacional, con una estruc- tura defensiva desconocida hasta ahora. Se trata de conjuntos realizados con obras estandarizadas (PT's, N/A's y barracones), estructura común y fechadas en los meses finales de la guerra. Se sitúan en ambas márgenes del río Cofio.

$4^{\circ}$. Localización, estudio, caracterización y documentación de un total de:

- 16 observatorios (11 nacionales/5 republicanos)

- 84 asentamientos de armas automáticas (60/24)

- 96 fortines y similares (28/69)

- 301 pozos de tirador (264/37)

- 292 obras de alojamiento para la tropa (174/118)

- 10 refugios para tropa $(5 / 5)$

- 9 emplazamientos para armas de tiro curvo (4/5)

- $4.302 \mathrm{~m}$ de caminos cubiertos (358/3.944)

- $28.744 \mathrm{~m}$ de trincheras (11.719/17.025)

- $11.920 \mathrm{~m}$ de parapetos (4.116/7.804) 
$5^{\circ}$. Caracterización geológica y petrológica de los diferentes CoDe's estudiados, para lo que se ha contado con la recogida de un total de un centenar de muestras de roca en la zona

$6^{\circ}$. Realización y carga de una base de datos específica para el almacenamiento de la información obtenida durante las campañas de campo, con un total de 86 campos.

$7^{\circ}$. Creación de un fondo documental gráfico de más de 4.000 fotogramas en color.

$8^{\circ}$. Obtención de un estudio fotogramétrico aéreo mediante un dron DJI Mavic Pro, dotado con cámara de 12,71 pixeles y tratamiento digital de las imágenes (modelos en 2D, 3D, MDT, etc.).

$9^{\circ}$. Análisis geomorfológico del paisaje y su posterior representación en un SIG.

El resultado final del proyecto: inventario de construcciones defensivas de la Guerra Civil, catalogación e inserción de las mismas en el medio natural, permitirá definir una serie de rutas y escenarios que facilitarán a los ciudadanos su conocimiento y disfrutar del bagaje histórico, cultural y patrimonial que representan, ampliando el concepto de paisaje natural al de paisaje geo-cultural.

\section{Agradecimientos}

A Carlos Lorenzo Carnicero (IGME), por su inestimable ayuda en los trabajos de fotogrametría mediante dron, lo que nos ha abierto nuevos horizontes para investigaciones posteriores.

A todas aquellas personas que no han abierto las puertas de sus fincas o nos han acompañado a los sitios que conocían con obras de la Guerra Civil o, sencillamente, nos han puesto sobre la pista de alguno de los hallazgos. A todos, muchas gracias.

$Y$ a todos los compañeros/compañeras del IGME que cuando les hemos pedido cualquier tipo de colaboración, fuese la que fuese, a pesar de la temática tan "particular" del trabajo, no han dudado en resolvernos el problema.

Pero no podemos finalizar estos agradecimientos sin recordar a quien cuando se le presentó la idea de lanzar un proyecto desde el IGME, de unas características tan novedosas como es este, lo entendió y lo apoyó; nos referimos a nuestro Director, Jorge Civis Llovera, tristemente desaparecido. ¡Gracias Jorge!.

\section{Referencias}

Álvarez Areces, E. y Baltuille Martín, J. M. 2017. Materiales pétreos y canteras para la construcción de las iglesias de San Miguel de Escalada (León) y San Cebrián de Mazote
(Valladolid). Arqueología y Territorio Medieval. 24, 115150. Jaén

Álvarez Areces, E., Fernández Suárez, J. y Baltuille Martín, J.M. 2016. La Alcazaba de Trujillo (Cáceres): evolución histórica y materiales pétreos empleados en su construcción. In: Gil Crespo, I.J. (ed.), Actas de las Segundas Jornadas sobre Historia, arquitectura y construcción fortificada, 41-44. Madrid.

Arévalo, J.M. 2008. Senderos de guerra. 20 rutas históricas por la sierra de Guadarrama. La Librería, $1^{\text {a }}$. ed., Madrid, 298 pp.

Baltuille Martín, J.M., Fernández Suárez, J., Álvarez Areces, E., Martínez-Martínez, J., Galván Blanco, J.A. and Molina Dorado, A. 2018. Preservación de las canteras históricas asociadas al patrimonio arquitectónico monumental. Proyecto INCHaPA. Digital Book of Articles of REHABEND 2018. 7th Euro-American Congress on Construction Pathology, Rehabilitation Technology and Heritage Management. Cáceres, 2615-2623.

Baltuille Martín, J.M., Álvarez Areces, E. and Fernández Suárez, J. 2016. Spanish inventory of historic quarries used in architectural heritage (INCHAPA). 5th International Conference YOuth in COnservation of CUltural Heritage YOCOCU 2016. Madrid.

Baltuille Martín, J.M., Rodríguez Nuere, B., Hernández Manchado, J.R. y Orozco Cuenca, Mª.T. 2015. El SIG/ PAM. Una herramienta informática, novedosa y flexible, para aplicar al Plan Nacional de Arquitectura Defensiva, a partir de la cartografía geológica nacional. Patrimonio Cultural de España, 9, 111-121.

Bellido, F., Capote, R., Casquet, C., Fúster, J.M., Navidad, M., Peinado, M. y Villaseca, C. 1981. Caracteres generales del Cinturón Hercínico en el Sector Oriental del Sistema Central Español. Cuadernos de Geología Ibérica, 7, 15-52.

Bellido Mulas, F., Casillas, R., Navidad, M., de Pablo García, J.G. Peinado Moreno, M., Villaseca, V., Ruiz García, M.T., Casquet, C., Macaya, J., González Casado, J.M., de Vicente, G., de Dios Centeno, J., Fernández, P., Villasante, R., Merlos, A., González Lodeiro, F., Alonso Millán, A., Armenteros, I., Dabrio, C., Pedraza, J., Pérez González, A. y Ruiz García, C. 1990b. Hoja n 532 LAS NAVAS DEL MARQUÉS. Mapa Geológico de España 1:50.000. IGME, $2^{\text {a }}$ ser., $1^{\text {a }}$ ed., 108 pp. y 1 map. Madrid.

Bellido Mulas, F., Martínez-Salanova, J., Martín Parra, L.M., del Olmo Sanz, A., Ruiz García, M.T., Casquet, C., Capote, R., González Casado, J.M., de Vicente, G., Bardají, T., Centeno, J.D., Fernández, P., Pedraza, J., Merlos, A., González Lodeiro, F., Alonso Millán, A., Armenteros, I. Dabrio, C., Díaz Molina, M., Bastida, J., Signes, M., López Martínez, N., Esteban Aenlle, J., Rodríguez, L.R. y Ruiz, C. 1990a. Hoja nº 533 SAN LORENZO DE EL ESCORIAL. Mapa Geológico de España 1:50.000. IGME, $2^{\text {a }}$ ser., $1^{\text {a }}$ ed., 98 pp. y 1 map. Madrid.

Capdevila, J. 1938. La fortificación de campaña. Sindicato de la Industria de la edificación, madera y decoración. CNT, $1^{\text {a }}$. ed., Barcelona, 266 pp. 
Castellano, R. 2004. Los restos del asedio. Fortificaciones de la Guerra Civil en el Frente de Madrid. Ejército nacional. Almena, $1^{\text {a }}$. ed., Madrid, 256 pp. y 1 CD.

Castellano, R. 2007. Los restos de la defensa. Fortificaciones de la Guerra Civil en el Frente de Madrid. Ejército republicano. Almena, $1^{\text {a }}$. ed., Madrid, 255 pp. y 1 CD.

Engel, C. 2005. Historia de las Brigadas Mixtas del Ejército Popular de la República 1936-1939. Almena, 2ª . ed., Madrid, $326 \mathrm{pp}$.

Engel, C. 2010. Historia de las Divisiones del Ejército Nacional 1936-1939. Almena, 2a . ed., Madrid, 247 pp.

Fernández Suárez, J., Álvarez Areces, E., Baltuille Martín, J.M. and Martínez-Martínez, J. 2017. Identificación, estudio preliminary puesta en valor de las canteras históricas de San Ciprián (Lugo). In: López-Morell, M.A., Baltuille, J.M. y Fernández Cortés, J. (eds.), Piedra Natural: Geología, economía y medioambiente. Boletín Geológico Minero. 128 (2), 485-498.

González Ruibal, A. 2008. Arqueología de la Guerra Civil española. Complutum, 19 (2). 11-20.

Julivert, M., Fontboté, J.Mª., Riveiro, A., y Navais Conde, L. 1972. Mapa Tectónico de la Península Ibérica y Balea- res, E. 1:1.000.000. Memoria explicativa. Instituto Geológico y Minero de España, 113 pp.

Martínez Bande, J.M. 1982. La Marcha sobre Madrid. Servicio Histórico Militar. Monografías de la Guerra de España, 1. San Martín, Madrid, 373 pp.

Pliego, D. 2009. Caminando por los escenarios de la Guerra Civil, Sierras del Rincón, Guadarrama y Malagón (28 excursiones). Desnivel, $1^{\text {a }}$ ed., Madrid, 280 pp.

Pliego, D. 2010. Caminando por los escenarios de la Guerra Civil, Sierras del Rincón, Guadarrama y Malagón (30 excursiones). Desnivel, $1^{\mathrm{a}}$ ed., Madrid, 273 pp.

Schnell Quiertant, P. y Baltuille Martín, J.M. 2017. Arqueología de la fortificación de la Guerra Civil y asociacionismo en los frentes de Madrid. Trabajos de Arqueología Navarra, 29, 169-202.

Schnell Quiertant, P. y de Arnaiz Seco, J.M. 2019. Manual descriptivo de obras militares de la Guerra Civil en la Comunidad de Madrid. In: García Valero, M.Á., Baquedano Beltrán, I. y Pastor Muñoz, F.J. (coord.), Plan Regional de fortificaciones de la Guerra Civil (1936-1939) de la Comunidad de Madrid. Comunidad de Madrid, Madrid, 99-130.

Recibido: julio 2020

Revisado: noviembre 2020

Aceptado: diciembre 2020

Publicado: marzo 2021 